\title{
Dark-spored species of Agaricineae from Republic of São Tomé and Príncipe, West Africa.
}

\author{
Desjardin $\mathrm{DE}^{1}$ and Perry $\mathrm{BA}^{2}$
}

${ }^{1}$ Department of Biology, San Francisco State University, 1600 Holloway Ave., San Francisco, California 94132, USA; ded@sfsu.edu

${ }^{2}$ Department of Biological Sciences, California State University East Bay, 25800 Carlos Bee Blvd., Hayward, California 94542,USA; brian.perry@csueastbay.edu

Desjardin DE, Perry BA 2016 - Dark-spored species of Agaricineae from Republic of São Tomé and Príncipe, West Africa. Mycosphere 7(3), 359-391, Doi 10.5943/mycosphere/7/3/8

\begin{abstract}
Eighteen dark-spored species representing members of the lineages Bolbitiaceae (Conocybe-1), Crepidotaceae (Crepidotus-2, Simocybe-1), Gymnopileae (Gymnopilus-2), Hymenogastraceae (Galerina-2), Psathyrellaceae (Coprinellus-2, Coprinopsis-2, Psathyrella-3), and Strophariaceae (Deconica-2, Hypholoma-1) are reported from the islands of São Tomé and Príncipe. Of these species, 4 are new species (Crepidotus kangoliformis, Coprinopsis afronivea, Psathyrella cacao, Psathyrella oboensis) and 11 are first reports for the Republic. New combinations are proposed for Deconica overeemii (Bas. Psilocybe overeemii) and Deconica protea (Bas. Agaricus proteus). Comprehensive descriptions, color photographs, ITS sequences and comparisons with allied taxa are provided.
\end{abstract}

Key words - Basidiomycota - fungal diversity - mushrooms - Gulf of Guinea

\section{Introduction}

In April 2006 (2 wk) and April 2008 (3 wk), expeditions led by scientists from the California Academy of Sciences and joined by mycologists from San Francisco State University visited the west African islands of São Tomé and Príncipe to document the diversity of plants, amphibians, marine invertebrates and macrofungi. This is the fourth in a series of papers focused on documenting the basidiomycetous macrofungi from the Republic (Desjardin \& Perry 2009, 2015a, 2015b).

The earliest record of dark-spored Agaricineae from the Republic of São Tomé and Príncipe is that of Fries (1851), who described two species from the island of "St. Thomae" as Agaricus (Naucoria) papularis Fr. and Agaricus (Galera) macromastes Fr. Saccardo and Berlese (1889) reported Coprinus cinereus (Schaeff.) Gray from São Tomé, and Bresadola and Roumeguère (1890) described Pholiota aculeata Bres. \& Roum. and Naucoria fusco-olivacea Bres. \& Roum. and reported Psathyrella disseminata (Pers.) Quél. from São Tomé. Coutinho (1925) reported nine species potentially belonging to the groups treated in this paper, viz., Coprinarius (Psathyrella) disseminatus (Pers.) P. Kumm., Inocybe reticulata Cout., Inocybe hystrix (Fr.) P. Karst., Naucoria (Flammula) papularis (Fr.) Sacc., Naucoria (Flammula) dilepis (Berk. \& Broome) Cout., Naucoria (Flammula) brevipes Cout., Naucoria (Flammula) aureobrunnea (Berk. \& M.A. Curtis) Cout., Naucoria (Flammula) chrysotricha (Berk. \& M.A. Curtis) Cout., and Pholiota aculeata Bres. \& 
Roum. Six of these thirteen taxa represented new species for the island of São Tomé. We have recollected four of the taxa listed above, and the remainder represent poorly known species or misapplied names. In addition, our fieldwork yielded four new species described herein, 11 new distribution reports for the islands, and two new nomenclatural combinations.

\section{Materials \& Methods}

Specimens were dried on a Nesco food dehydrator, packed in airtight plastic bags and hand carried back to the US. Macromorphological data were derived from fresh specimens, whereas micromorphological data were derived from dried specimens rehydrated in ethanol followed by distilled water, $3 \% \mathrm{KOH}$ or Melzer's reagent. Color terms and notations are those of Kornerup and Wanscher (1978). All cited specimens are deposited in the H.D. Thiers Herbarium, Dept. of Biology, San Francisco State University (SFSU).

Total genomic DNA was extracted from dried material using the Extract-N-Amp Plant PCR Kit (Sigma-Aldrich, St. Louis, MO) following the manufacturers instructions. PCR protocols followed those outlined in Perry et al. (2007). The nuclear ribosomal internal transcribed spacer region (ITS) was amplified using primers ITS1-F/ITS4 (Gardes and Bruns 1993; White et al. 1990), and amplification products were sent to Beckman Coulter (Danvers, MA) for sequencing. Resulting sequencing products were edited and assembled in Geneious 9.0 (Biomatters Ltd., Auckland, New Zealand). All ITS sequences generated as part of this study have been deposited in GenBank (accessions KX017198- KX017215).

Phylogentic analyses were performed to further investigate the taxonomic affinities of the African material of Hypholoma. ClustalX (Larkin et al. 2007) and Mesquite (Maddison and Maddison 2015) were used to align sequences of the African material of Hypholoma within a broader sampling of the genus downloaded from GenBank. Maximum likelihood analyses were run in RAxML 8.2.4 (Stamatakis 2014) under a GTRGAMMA model and consisted of 100 alternative runs using the default parameters, with node support estimated by 500 RAxML bootstrap replicates. Bayesian analyses were performed using Metropolis Coupled MCMC methods as implemented in MrBayes 3.2.6 (Huelsenbeck \& Ronquist 2001; Ronquist \& Huelsenbeck 2003) under a GTR $+\mathrm{G}$ model of sequence evolution as determined under the Bayesian Information Criterion in jModelTest 2.1.7 (Darriba et al. 2012, Guindon \& Gascuel 2003). Bayesian analyses consisted of two parallel searches, run for 12 million generations and initiated with random starting trees. Eight chains were sampled every 5000 generations for a total of 2001 trees each, sampled from the posterior distribution. Those trees sampled prior to the runs reaching an average standard deviation of split frequencies of 0.01 were discarded as the burnin, while the remaining trees were used to calculate the posterior probabilities of the individual clades. Default settings were used in MrBayes to set unconstrained branch lengths and uninformative topology priors. The aligned Hypholoma ITS dataset and associated tree file have been deposited in TreeBase (submission \#19146).

\section{Taxonomy}

\section{Bolbitiaceae}

Conocybe zeylanica (Petch) Boedijn, Sydowia 5(3-6): 223. 1951. Fig. 1a-d Basionym: Galera zeylanica Petch, Ann. R. Bot. Gdns. Peradeniya 6(4): 317. 1917. Potential synonyms: refer to Pegler (1986).

Pileus $33 \mathrm{~mm}$ diam, broadly conico-convex, margin striatulate; surface dull, dry, glabrous, disc brown, margin yellowish brown with orange tones (5C-D5-6). Context thin (1 mm), concolorous with surface. Lamellae adnate, crowded with 3 series of lamellulae, occasionally forked, moderately broad, rusty brown. Stipe $85 \times 1.5$ (apex) $\times 4$ (base) $\mathrm{mm}$, central, terete, gradually enlarged downward, hollow; surface dull, dry, minutely pubescent, apex off-white, base becoming brown. 


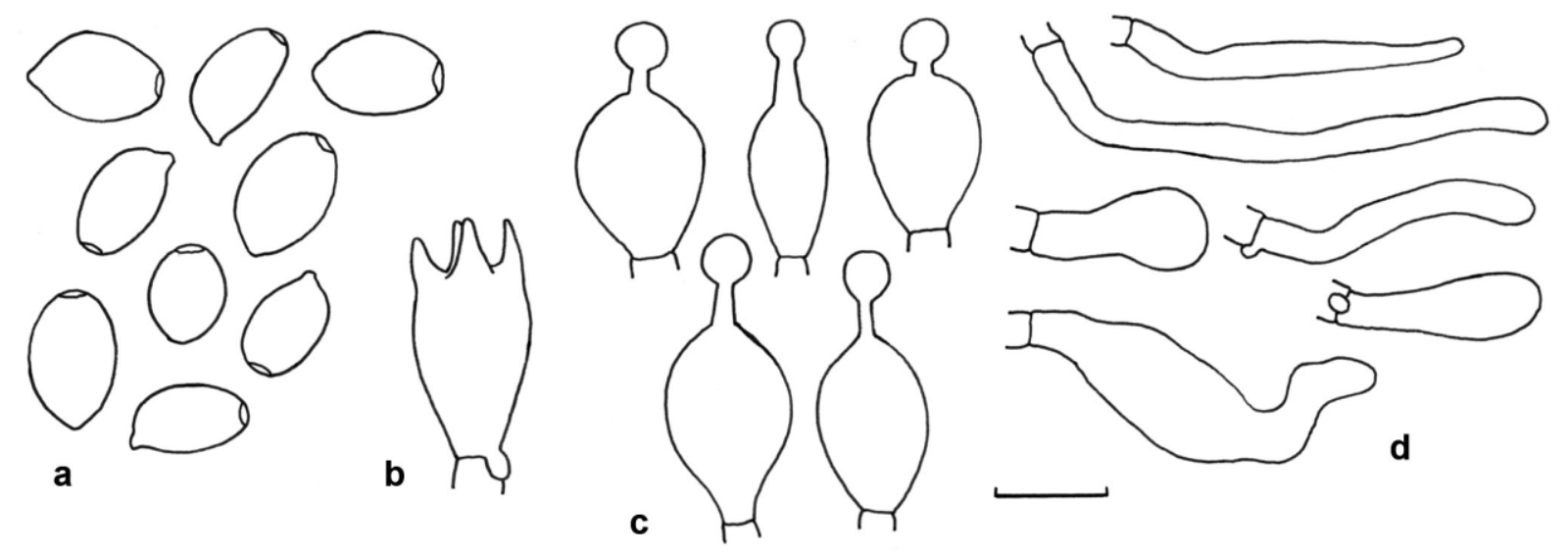

Fig. 1 - Micromorphological features of Conocybe zeylanica (BAP665). a. Basidiospores. b. Basidium. c. Cheilocystidia. d. Caulocystidia. Scale bar $=10 \mu \mathrm{m}$

Basidiospores 9.5-11.5 × 7.4-8.0 $\mu \mathrm{m}$ (face view) $\times 6.4-7.0 \mu \mathrm{m}$ (profile) $\mu \mathrm{m}$, ellipsoid to sublimonifirm in face view, lentiform in profile, smooth, orangish brown, thick-walled, with a prominent germ pore. Basidia 19-25 × 11-13 $\mu \mathrm{m}$, broadly clavate, 4-spored, separated by prominent pseudoparaphyses. Pleurocystidia absent. Cheilocystidia scattered, 19-26 × 7-12 $\mu \mathrm{m}$, broadly lecythiform, with a globose capitulum 3-5 $\mu \mathrm{m}$ diam elevated on a pedicel 1.2-4 $\mu \mathrm{m}$ long, hyaline, thin-walled. Pileipellis an epithelium of broadly clavate to vesiculose or sphaeropedunculate cells 8-22 $\mu \mathrm{m}$ diam, hyaline to golden brown, thin-walled; pileocystidia not observed. Stipitipellis a cutis of repent hyphae 2.5-7 $\mu \mathrm{m}$ diam, cylindrical, smooth, hyaline, thinwalled. Caulocystidia clustered, of two types: 1) cylindrical, 20-48 $\times 2.5-4 \mu \mathrm{m}$, obtuse; 2) clavate to ventricose, $16-30 \times 5.5-8 \mu \mathrm{m}$; hyaline, thin-walled. Clamp connections present.

Habitat and known distribution - Solitary in soil in mixed forest of cacao and native trees. Africa (São Tomé, Tanzania), India, Indonesia (Java), Sri Lanka, in a greenhouse in The Netherlands.

Material examined - Africa, São Tomé island, along road to Bombain, $400 \mathrm{~m}$ elev., N0¹6.625', E6 ${ }^{\circ} 38.942 '$ ', 26 Apr. 2008, coll. by B.A. Perry and D.E. Desjardin, BAP665 (SFSU; KX017198).

Notes - The São Tomé specimen of Conocybe zeylanica, a species described originally from Sri Lanka, is characterized by rather large basidiomes with glabrous, yellowish orange-brown pilei over $30 \mathrm{~mm}$ diam, a long $(85 \mathrm{~mm})$, pubescent stipe with clavate and cylindrical caulocystidia and lacking lecythiform cells, basidiospores in the range 9.5-11.5 × 7.4-8.0 × 6.4-7.0 $\mu \mathrm{m}$, broadly lecythiform cheilocystidia with globose capitulum 3-5 $\mu \mathrm{m}$ diam, and growth in soil. Pegler (1977) reported the species from Tanzania with basidiospores 12-16 $\times 7.5-9.5 \mu \mathrm{m}$, whereas Horak and Hausknecht (2002) reported the species from "subtropical to tropical regions" as having basidiospores $9.5-14.5 \times 6.0-8.0 \mu \mathrm{m}$.

Conocybe zeylanica is closely allied with $C$. apala (Fr.) Arnolds, a common species in lawns and other grasslands in temperate habitats, but the latter has a much paler pileus described as white to cream with an ochraceous disc compared to the yellowish brown to orange pileus of $C$. zeylanica. An ITS sequence of BAP665 from São Tomé is 98.8\% similar to a sequence in GenBank determined as C. apala strain xsd08120 (FJ481031) from China.

\section{Crepidotaceae}

Crepidotus kangoliformis Desjardin \& B.A. Perry, sp. nov.

Figs. 2, 3a-f Mycobank MB 816218

Diagnosis - Pileus 7-21 mm diam, broadly convex to flabelliform, radially appressedfibrillose to minutely squamulose, dingy white with rusty brown fibrils. Lamellae close to crowded, 
moderately broad, pinkish brown. Stipe nearly lateral, up to $2 \times 1 \mathrm{~mm}$; surface covered with reddish brown appressed fibrils. Basidiospores mostly 5.5-6.5 $\mu \mathrm{m}$ diam, a small percentage 7-8 $\mu \mathrm{m}$ dam, globose, echinulate, thick-walled, brown. Basidia 2- and 4-spored. Pleurocystidia 27-42 $\times$ 7-10 $\mu \mathrm{m}$, fusoid-ventricose to ventricose with a long neck. Cheilocystidia 42-52 $\times 8-12.5 \mu \mathrm{m}$, cylindrical to subclavate, seldom subcapitate. Pileipellis a cutis with chains of smooth or incrusted hyphae 30-64 × 6-12 $\mu \mathrm{m}$ diam, walls hyaline to pale golden brown, pigment intraparietal, incrustations hyaline; terminal cells 32-68 $\times 5.5-10 \mu \mathrm{m}$, cylindrical to fusoid. Caulocystidia 20-78 $\times 6.5-12 \mu \mathrm{m}$, subcylindrical to subfusoid, ventricose or clavate, often wavy in outline, smooth, golden brown or paler. Clamp connections present. Gregarious on decayed wood in primary montane forest. Holotype: Africa, São Tomé island, Macambrara, 25 April 2008, coll. by B.A Perry \& D.E. Desjardin, BAP664 (SFSU; KX017199).

Etymology - having the form of a wool Kangol hat.

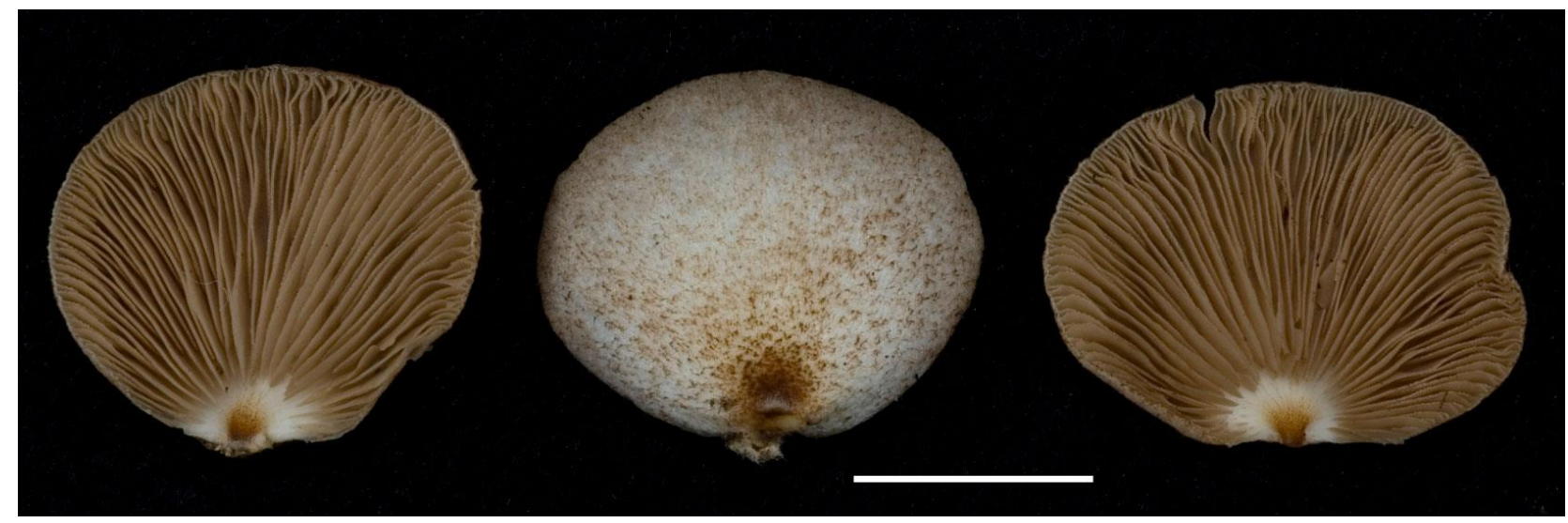

Fig. 2 - Basidiomes of Crepidotus kangoliformis (Holotype, BAP664). Scale bar = $10 \mathrm{~mm}$.

Pileus 7-21 mm diam, broadly convex in profile, ovoid to flabelliform in face view, nonstriate; surface dull, dry, radially appressed-fibrillose to minutely squamulose, dingy white with rusty brown fibrils. Context 1-2 mm thick, soft, white. Lamellae subfree, close to crowded with 23 series of lamellulae, moderately broad (up to $2 \mathrm{~mm}$ ), pinkish brown. Stipe reduced, nearly lateral, up to $2 \times 1 \mathrm{~mm}$, tapered; surface dull, dry, covered with reddish brown appressed fibrils; area between lamellae and stipe white. Odor mildly phenolic.

Basidiospores mostly 5.5-6.5 $\mu \mathrm{m}$ diam, a small percentage 7-8 $\mu \mathrm{m}$ diam, globose, echinulate, thick-walled, brown. Basidia both 2-spored and 4-spored; 2-spored basidia 28-32 $\times$ 6.5-8 $\mu \mathrm{m}$, elongate-urniform, projecting up to $16 \mu \mathrm{m}$ beyond basidioles; 4-spored basidia 20-23 $\times$ 6.5-8 $\mu \mathrm{m}$, clavate or rarely urniform, typically not projecting. Basidioles broadly clavate. Pleurocystidia common, 27-42 × 7-10 $\mu \mathrm{m}$, fusoid-ventricose to ventricose with a long neck, hyaline, thin-walled, projecting slightly beyond basidioles. Cheilocystidia abundant, lamellar edge sterile, $42-52 \times 8-12.5 \mu \mathrm{m}$, cylindrical to subclavate, seldom subcapitate, broadly obtuse, hyaline, thin-walled. Pileipellis a cutis with chains of smooth or incrusted hyphae 30-64 × 6-12 $\mu \mathrm{m}$ diam, walls hyaline to pale golden brown, pigment intraparietal, incrustations hyaline; terminal cells $32-$ $68 \times 5.5-10 \mu \mathrm{m}$, cylindrical to fusoid, obtuse. Pileus trama interwoven, hyphae 5-8 $(-10) \mu \mathrm{m}$ diam, cylindrical, much branched, hyaline, thin-walled. Stipe tissue composed of hyphae 5-13 $\mu \mathrm{m}$ diam, irregular in outline, smooth, hyaline, thin- to thick-walled. Caulocystidia abundant, 20-78 $\times 6.5-12$ $\mu \mathrm{m}$, subcylindrical to subfusoid, ventricose or clavate, often wavy in outline, smooth, golden brown or paler, thin-walled. Clamp connections present.

Habitat and known distribution - Gregarious on decayed wood in primary montane forest. Africa (São Tomé).

Material examined - Africa, São Tomé island, Macambrara, radio antenna area, $1300 \mathrm{~m}$ elev., N0¹6.557', E0³6.326', 25 April 2008, coll. by B.A Perry \& D.E. Desjardin, BAP664 (Holotype, SFSU; KX017199). 


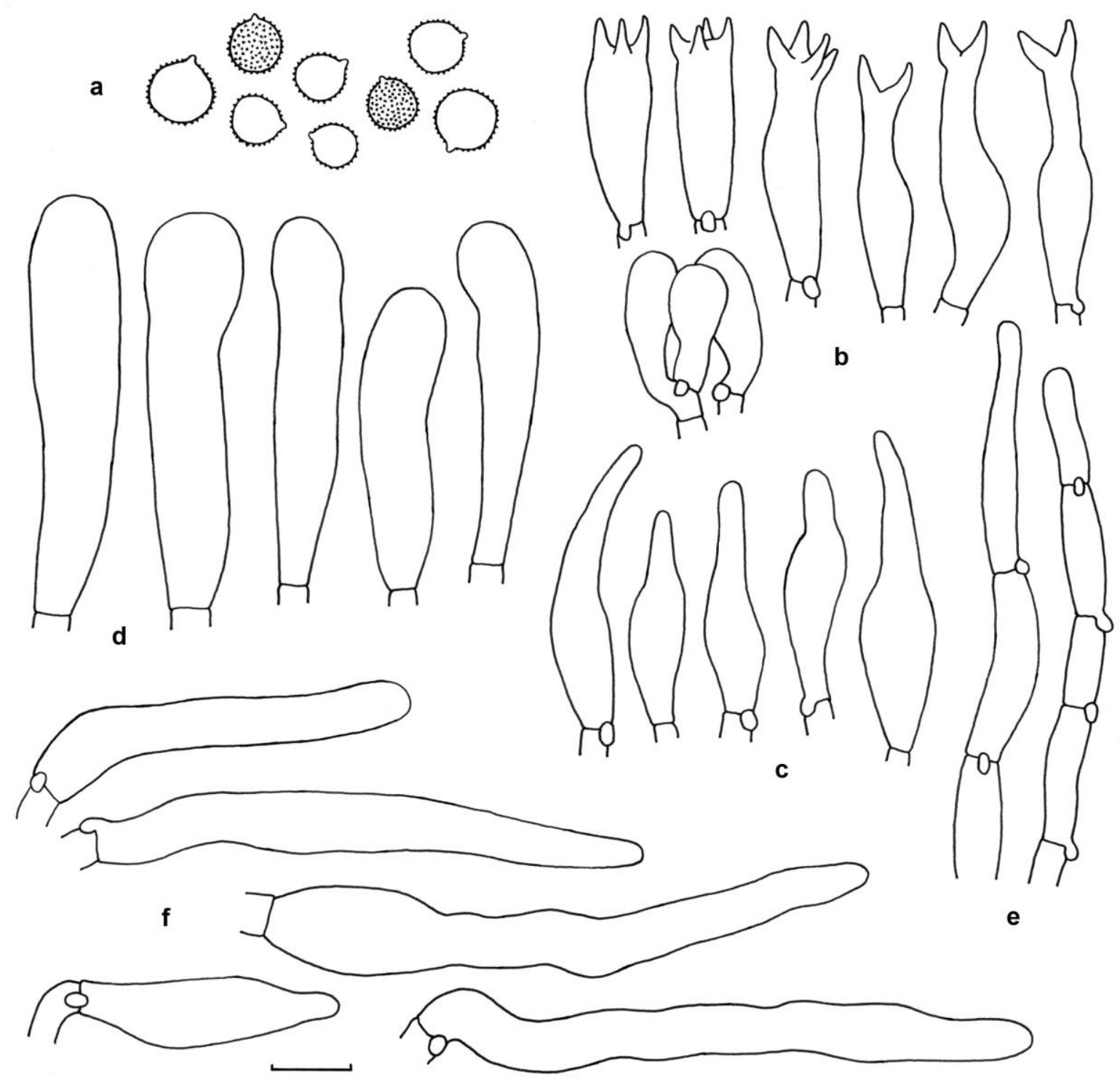

Fig. 3 - Micromorphological features of Crepidotus kangoliformis (Holotype, BAP664). a. Basidiospores. b. Basidia and basidioles. c. Pleurocystidia. d. Cheilocystidia. e. Pileipellis hyphae. f. Caulocystidia. Scale bar $=10 \mu \mathrm{m}$

Notes - Distinctive features of Crepidotus kangoliformis include a dingy white pileus with rusty brown fibrils, a reduced, lateral stipe, globose basidiospores of two sizes (5.5-6.5 $\mu \mathrm{m}$ and 7-8 $\mu \mathrm{m}$ diam), numerous elongate-urniform 2-spored basidia that project up to $16 \mu \mathrm{m}$, cylindrical to subclavate cheilocystidia, and a cutis-type pileipellis of chains of short-celled, incrusted hyphae. The species belongs in Subgen. Sphaerula, Sect. Sphaerula, Subsect. Fulvifibrillosi of Hesler and Smith (1965), where it is similar to C. appalachianensis Hesler \& A.H. Sm. and C. subfibrillosus Hesler \& A.H. Sm. Crepidotus appalachianensis differs in lacking a reduced lateral stipe covered with golden brown caulocystidia, lacking elongate-urniform 2-spored basidia and in forming shorter cheilocystidia $(28-48 \mu \mathrm{m})$ (Hesler \& Smith 1965). Crepidotus subfibrillosus differs in forming a cinnamon buff pileus, lacks a reduced lateral stipe, has narrower hymenial cystidia (5-8 $\mu \mathrm{m})$, non-incrusted pileipellis hyphae, and grows on logs of Fraxinus in a temperate habitat in Michigan (USA) (Hesler \& Smith 1965). An ITS sequence of BAP664 showed 97.4-97.6\% similarity to several Japanese specimens (KF680279, KF680280) determined as C. crocophyllus (Berk.) Sacc. (Kasuya et al. 2014), a species described from temperate North America with orange lamellae (Hesler \& Smith 1965). 
Crepidotus nephrodes (Berk. \& M.A. Curtis) Sacc., Syll. Fung. (Abellini) 5: 882. 1887.

Basionym: Agaricus nephrodes Berk. \& M.A. Curtis, Ann. Mag. Nat. Hist., Ser. 2, 12: 422.1853.

Pileus 6-22 $\mathrm{mm}$ diam, hemispherical to convex in profile, ovoid to reniform in face view, non-striate; surface dull, moist, appressed-pubescent, dingy white with a few brown fibrils. Context 2-3 mm thick, soft, white. Lamellae adnexed to point of attachment, close with 3-4 series of lamellulae, broad (up to $3 \mathrm{~mm}$ ), white becoming brownish gray to tawny (6C3). Stipe absent.

Basidiospores 5.2-6.5 $\mu \mathrm{m}$ diam, globose, finely echinulate, thick-walled, yellowish brown to brownish orange. Basidia 17.5-21 $\times 7-8 \mu \mathrm{m}$, clavate, 4-spored. Basidioles clavate. Pleurocystidia absent. Cheilocystidia abundant, lamellar edge sterile, 38-52 × 9.5-13.5 $\mu \mathrm{m}$, clavate, broadly obtuse, seldom subcapitate, hyaline, thin-walled. Pileipellis a cutis with chains of hyphae 3.5-6.5 $\mu \mathrm{m}$ diam, cylindrical, smooth, non-incrusted, hyaline; terminal cells similar but slightly thick-walled, hyaline to pale brown. Pileus trama hyphae similar to pileipellis hyphae. Clamp connections present.

Habitat and known distribution - Scattered on fallen palm debris in secondary forest.

Material examined - Africa, Príncipe island, east side of island at base of Dois Irmãos, N1³4.889', E7²5.548', 23 April, coll. by D.E. Desjardin, DED8316 (SFSU; KX017200).

Notes - Pegler (1977) reported Crepidotus nephrodes from east Africa (Kenya, Tanzania), although the species was described originally from South Carolina (USA), with the caveat that it had been shown to have a wide neotropical distribution. Without more evidence to refute his diagnosis, we follow Pegler in determining the material from Príncipe as representing $C$. nephrodes. Our material differs slightly from other African material in forming larger cheilocystidia $(38-52 \times 9.5-13.5 \mu \mathrm{m}$ versus $28-37 \times 3.5-9 \mu \mathrm{m})$ and in growing on palm debris. An ITS sequence of DED8316 has a closest BLAST match to C. applanatus (Pers.) P. Kumm. with $86 \%$ similarity.

Simocybe centunculus (Fr.) P. Karst., Bidr. Känn. Finl. nat. Folk 32: 420. 1879.

Figs. 4, 5a-d

Basionym: Agaricus centunculus Fr., Syst. Mycol. (Lundae) 1: 262. 1821.

= Naucoria centunculus (Fr.) P. Kumm., Führ. Pilzk. (Zerbst): 78. 1871.

= Ramicola centunculus (Fr.) Watling, Notes R. Bot. Gdn. Edinb. 45(3): 555.1989 (1988).

Pileus 7-13 mm diam, convex to plano-convex, becoming plane-depressed, margin striate; surface dull, dry, rugulose, minutely granulose-pruinose, dark yellowish brown (5F5-8) with olivaceous tones. Context $0.5 \mathrm{~mm}$ thick, watery-concolorous with surface. Odor and taste indistinct. Lamellae horizontal, adnexed to adnate, subdistant with 3 series of lamellulae, broad ( -2 $\mathrm{mm}$ ), yellowish olive-brown (5E5-6), edges white-pruinose. Stipe 12-15 × $1 \mathrm{~mm}$, central, terete, cylindrical, stuffed; surface dull, dry, pruinose to hispidulous overall, cream (4A3) to light yellowish brown (5D4-5) with olivaceous tones or paler.

Basidiospores 6.4-7.5 × 4-5 $\mu \mathrm{m}\left[\mathrm{x}=6.9 \pm 0.4 \times 4.5 \pm 0.3 \mu \mathrm{m}, \mathrm{Q}=1.4-1.7, \mathrm{Q}_{\mathrm{m}}=1.54 \pm\right.$ $0.08, \mathrm{n}=20, \mathrm{~s}=1$ ], ellipsoid to phaseoliform, smooth, lacking a germ pore, yellowish brown, inamyloid, thick-walled. Basidia 19-22 × 7-9 $\mu \mathrm{m}$, clavate, 4-spored. Basidioles clavate to subclavate. Cheilocystidia abundant, lamellar edge sterile, 32-42 $\times 6.5-9.5 \mu \mathrm{m}$, cylindrical to subventricose or seldom lageniform, obtuse, not capitate, apex 4.8-7 $\mu \mathrm{m}$ diam, hyaline, inamyloid, thin-walled. Pleurocystidia absent. Pileipellis nearly a palisade with numerous erect pileocystidia arising from inflated to vesiculose cells 10-20 $\mu \mathrm{m}$ diam; terminal cells (pileocystidia) 27-48 $\times 7$ $15 \mu \mathrm{m}$, subcylindrical to fusoid-ventricose or lageniform, obtuse, not capitate, hyaline to brown, thin-walled or basally slightly thick-walled, subtending cells sometimes in short chains. Pileus trama interwoven, hyphae 3.5-13 $\mu \mathrm{m}$ diam, cylindrical to inflated, smooth, hyaline to brown, thinwalled. Lamellar trama similar to pileus trama. Stipe cortical hyphae 4-8 $\mu \mathrm{m}$ diam, short-celled, cylindrical, smooth, hyaline to pale yellowish brown, mostly unclamped; medullary hyphae similar but up to $13 \mu \mathrm{m}$ diam. Caulocystidia scattered, abundant, similar to pileocystidia and cheilocystidia, lageniform to subventricose, not capitate. Clamp connections present but not at every septum. 


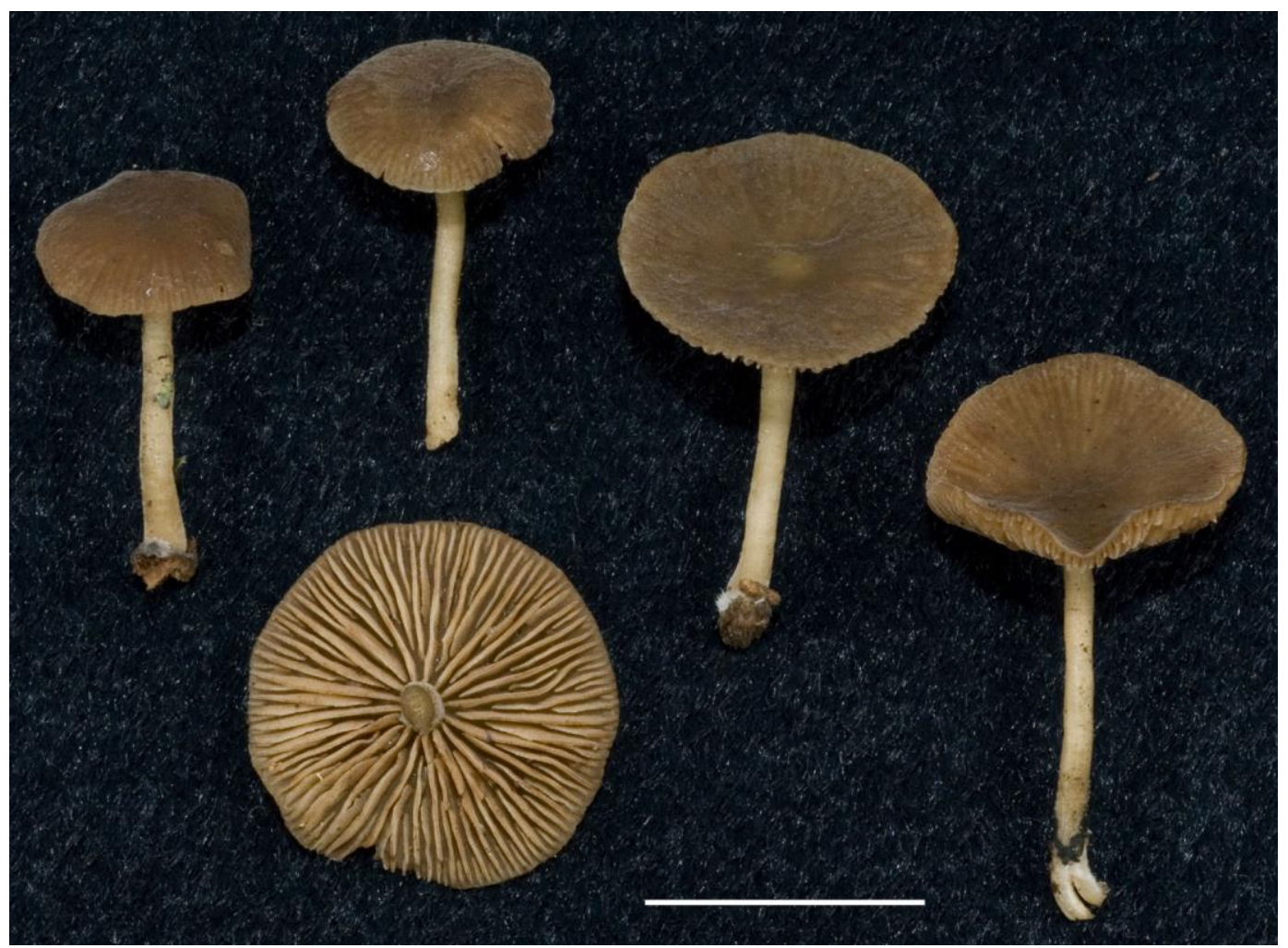

Fig. 4 - Basidiomes of Simocybe centunculus (DED8258). Scale bar $=10 \mathrm{~mm}$.

Habitat and known distribution - Solitary on very rotten wood in coastal secondary forest. Africa (São Tomé).

Material examined - Africa, São Tomé island, along main road (EN-1) on north side of island at $18.25 \mathrm{~km}$ marker, Shipwreck Cove, N0²3.687', E6 ${ }^{\circ} 36.302^{\prime}, 17$ April 2008, col. by D.E. Desjardin, DED8258 (SFSU).

Notes - Simocybe centunculus is distinguished by small basidiomes with dark yellowish olive-brown, rugulose pileus, subdistant, yellowish olive-brown lamellae, a short $(12-15 \mathrm{~mm})$, hispidulous, cream to light yellowish brown stipe, ellipsoid to phaseoliform, yellowish brown basidiospores with mean $6.9 \times 4.5 \mu \mathrm{m}$, cylindrical to subventricose cheilocystidia, a palisade-type pileipellis with subcylindrical to fusoid-ventricose pileocystidia that arise from inflated to vesiculose cells, lageniform to subventricose caulocystidia, and growth on rotten wood. The São Tomé specimen is macromorphologically indistinguishable from north temperate (North American and Europe) material of $S$. centunculus, but the latter differs subtly by forming slightly smaller basidiospores $(5.0-6.2(-7.0) \times 3.5-4.2(-4.75) \mu \mathrm{m})$ and a more cellular pileipellis (Reid 1984). This species is similar to Naucoria fusco-olivacea Bres. \& Roum., described from São Tomé by Bresadola and Roumeguère (1890) and compared by them to Simocybe centunculus (as Naucoria centuncula), however, $N$. fusco-olivacea forms a longer $(60-70 \mathrm{~mm})$, reddish brown ("rufo-fuscus") stipe, and larger basidiospores $(8-10 \times 5-6 \mu \mathrm{m})$. Several attempts to generate quality ITS sequences from DED8258 were unsuccessful.

\section{Gymnopileae}

Gymnopilus aureobrunneus (Berk. \& M.A. Curtis) Murrill, Mycologia 5: 19. 1913. Figs. 6, 7a-c Basionym: Agaricus aureobrunneus Berk. \& M.A. Curtis, J. Linn. Soc., Bot. 10(45): 289. 1868 (1869).

= Naucoria aureobrunnea (Berk. \& M.A. Curtis) Cout., Anais Inst. sup. Agron. Univ. Téc. Lisboa 2: 21.1925.

= Flammula aureobrunnea (Berk. \& M.A. Curtis) Sacc., Syll. Fung. (Abellini) 5: 813. 1887. 

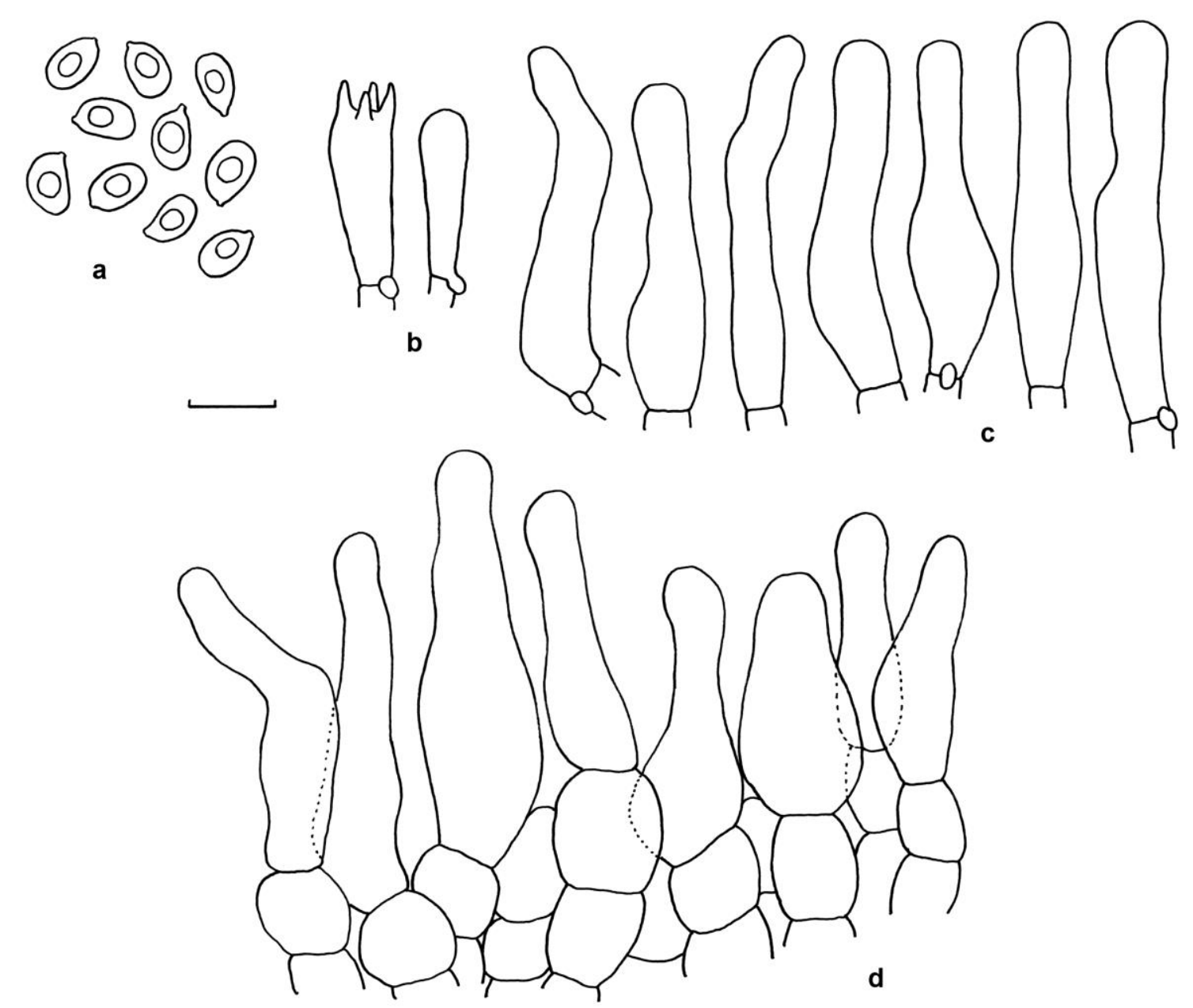

Fig. 5 - Micromorphological features of Simocybe centunculus (DED8258). a. Basidiospores. b. Basidium and basidiole. c. Cheilocystidia. d. Pileipellis. Scale bar $=10 \mu \mathrm{m}$

Pileus 16-33 mm diam, broadly plano-convex to plane, plano-umbonate or planodepressed; surface dull, moist, appressed-fibrillose to glabrous, light yellowish orange to light orange (4-5A4) or golden yellow (5B6-7), darker in age. Context 1-2 mm thick, pale yellowish cream (4A3). Odor indistinct; taste bitter. Lamellae adnate, close to subdistant with 3-4 series of lamellulae, broad (3-4 mm), brownish orange (6C5-6). Stipe 10-30 × 1.5-3 mm, central, terete, cylindrical, curved, narrowly hollow; surface dull, dry, glabrous, pale yellow (3-4A2), becoming darker in age to grayish orange (5B3-4). Partial veil cortinate, evanescent, yellowish orange, leaving no or a few fibrils on the stipe apex.

Basidiospores 6-7.7 $\times 4.5-5.5 \mu \mathrm{m}(\mathrm{x}=7 \times 5 \mu \mathrm{m})$, ellipsoid, finely verruculose, plage absent, rusty brown. Basidia 16-20 $\times 6.5-8 \mu \mathrm{m}$, clavate, with sterigmata up to $7 \mu \mathrm{m}$ long, 4-spored, rarely 2-spored. Pleurocystidia absent. Cheilocystidia scattered, 20-26 × 5.7-7 $\mu \mathrm{m}$, lageniform, hyaline, thin-walled. Pileipellis a cutis of radially arranged hyphae 3-12 $\mu \mathrm{m}$ diam, cylindrical or slightly inflated, hyaline to orange, pigment cytoplasmic, thin-walled, non-incrusted, nongelatinous; terminal cells undifferentiated. Pileus trama hyphae 3-20 $\mu \mathrm{m}$ diam, cylindrical to inflated, hyaline. Lamellar trama hyphae similar. Clamp connections present.

Habitat and known distribution - Solitary on rotten fallen coconut palm trunk in coastal coconut grove. Africa (Kenya, São Tomé, Tanzania), Cuba.

Material examined - Africa, São Tomé island, along main road (EN-2) on south side of island, N0 12.126 ', E6 $6^{\circ} 42.362^{\prime}, 13$ April 2008, coll. by D.E. Desjardin, DED8221 (SFSU; KX017201). 


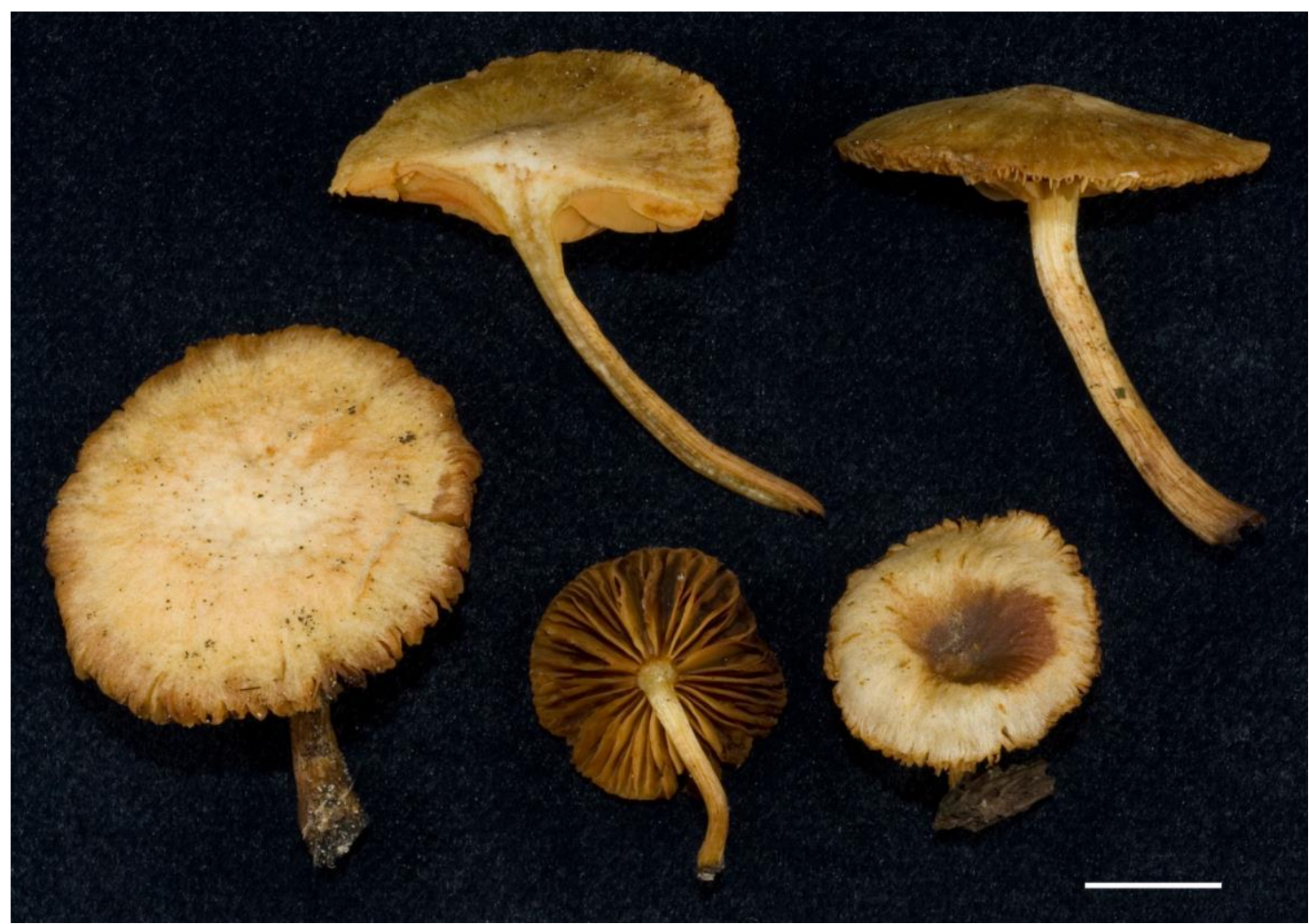

Fig. 6 - Basidiomes of Gymnopilus aureobrunneus (DED8221). Scale bar $=10 \mathrm{~mm}$.
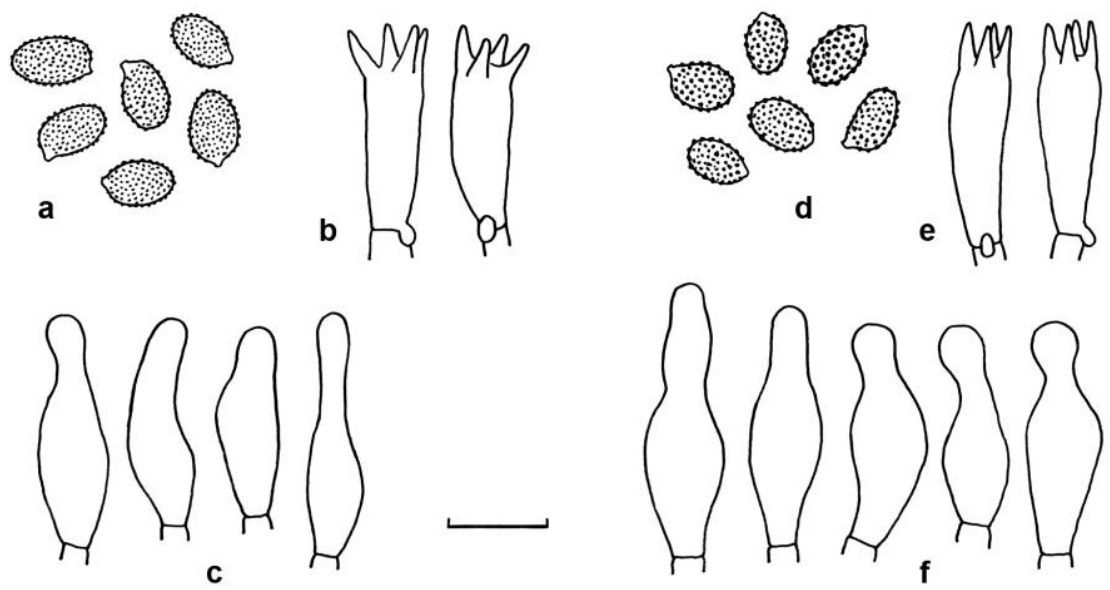

Fig. 7 - Micromorphological features of Gymnopilus aureobrunneus (a-c; DED8221) and Gymnopilus purpureosquamulosus (d-f; DED8302). a, d. Basidiospores. b, e. Basidia. c, f. Cheilocystidia. Scale bar $=10 \mu \mathrm{m}$.

Notes - Gymnopilus aureobrunneus is characterized by a plano-convex-depressed, golden yellow, appressed-fibrillose pileus, adnate, brownish orange lamellae, a pallid, grayish orange stipe lacking obvious partial veil remnants, a cortinate, evanescent partial veil, finely verruculose basidiospores lacking a plage with mean $7 \times 5 \mu \mathrm{m}$, lageniform cheilocystidia, and growth on coconut palm trunks. It was reported from São Tomé by Coutinho (1925, as Naucoria aureobrunnea) from material growing on palm trunks. The São Tomé specimen reported here is composed of rather old basidiomes with nearly glabrous pileus and stipe, but the micromorphology with finely verruculose basidiospores and lageniform cheilocystidia are distinctive. 
Gymnopilus aureobrunneus belongs to what appears to be a morphologically variable but molecularly similar group of species denoted the "lepidotus-subearlei" clade by Guzmán-Dávalos et al. (2003). An ITS sequence of DED8221 is 99.6-99.8\% similar to six species with distinct morphologies, viz., G. lepidotus Hesler (AY280989 from Mexico), G. ochraceus Høil. (EU401709 from Zimbabwe), G. dilepis (Berk. \& Broome) Singer (AY280980 from Malaysia), G. medius Guzm.-Dáv. (AY280994 from Mexico), G. subearlei R. Valenz., Guzmán \& J. Castillo (AY281013 from Mexico), and "G." cerasinus (AY280978, locality unknown). Indeed, ITS sequences of these six taxa differ in only 0-2 base pairs (Guzmán-Dávalos et al. 2008), prompting the authors to state "we have to assume that the high similarity of ITS sequences ... does not necessarily mean conspecificity." Based on morphology, the São Tomé material best matches African descriptions of G. aureobrunneus (Coutinho 1925, Pegler 1977).

Gymnopilus purpureosquamulosus Høiland, Mycotaxon 69: 82. 1998.

Fig. $7 \mathrm{~d}-\mathrm{f}$

Possible heterotypic synonyms: refer to Guzmán-Dávalos et al. (2008).

Pileus 8-25 mm diam, convex or campanulate, sometimes with a broad umbo, expanding to plano-convex-depressed; disc covered with small, erect, reddish brown (9E7-8) squamules; margin glabrous; surface dry, grayish orange (5B4-5) to orangish white (5A3) to yellowish white (4A2). Context 1-2 mm thick, buff to pale yellowish white (3A2). Lamellae shallowly adnexed becoming adnate with a decurrent tooth, subdistant with 2 series of lamellulae, broad $(2-5 \mathrm{~mm})$, light orange (5A4) becoming orange (6B4-5) to brownish orange (6C4) in age. Spore deposit bright reddish orange (7B8). Stipe 10-30 × 1.5-2 mm, central, terete, cylindrical above a swollen to subbulbous base, hollow, curved; surface dull, dry, glabrous, grayish orange (5B4-5) with a few reddish streaks, base reddish brown (8D6-8). Partial veil a cortina, soon evanescent, leaving yellowish orange to grayish orange fibrils on the pileus margin and an annular zone on stipe apex.

Basidiospores 6-7 $\times 4.2-4.8 \mu \mathrm{m}(\mathrm{x}=6.5 \times 4.5 \mu \mathrm{m})$, ellipsoid to amygdaliform, often with a suprahilar depression, coarsely verrucose, plage absent, rusty brown. Basidia 19-22 × 6.5-7 $\mu \mathrm{m}$, clavate, 4-spored. Pleurocystidia absent. Cheilocystidia abundant, lamellar edge sterile, 20-28 $\times 7-$ $8 \mu \mathrm{m}$, utriform to lageniform, sometimes subcapitate, hyaline, thin-walled. Pileipellis a cutis of radially arranged hyphae 3-10 $\mu \mathrm{m}$ diam, cylindrical, hyaline to orange, thin-walled, non-incrusted, non-gelatinous; terminal cells subcylindrical to clavate, in erect to suberect clusters. Pileus trama hyphae 3-16 $\mu \mathrm{m}$ diam, cylindrical to inflated, hyaline. Lamellar trama hyphae 4.5-16 $\mu \mathrm{m}$ diam, inflated, hyaline. Clamp connections present.

Habitat and known distribution - Scattered to gregarious on undetermined wood in coastal palm and banana groves. Africa, Southeast Asia

Material examined - Africa, Príncipe island, Bom Bom resort area, N1 ${ }^{\circ} 41.559^{\prime}, \mathrm{E}^{\circ} 24.171^{\prime}$, 22 April 2008. coll. by D.E. Desjardin, DED8302 (SFSU; KX017202); São Tomé island, along main road on north side of island, west of Rio Luisa at $33 \mathrm{~km}$ marker, N0 ${ }^{\circ} 19.607^{\prime}, \mathrm{E}^{\circ} 30.666^{\prime}, 26$ April 2006, coll. by D.E. Desjardin (material lost).

Notes - The Príncipe specimen of Gymnopilus purpureosquamulosus is characterized by an orange pileus with reddish brown erect squamules on the disc, adnate-subdecurrent lamellae, an orange to reddish brown stipe, an evanescent, cortinate partial veil, coarsely verrucose basidiospores lacking a plage with mean $6.5 \times 4.5 \mu \mathrm{m}$, utriform-lageniform cheilocystidia, and growth on woody debris in palm groves. An ITS sequence of DED8302 from Príncipe showed 99.8-99.9\% similarity to two GenBank sequences (AY280979 from Nigeria; AY280998 from Switzerland) determined as G. purpureosquamulosus. Høiland (1998) reported the species only from Zimbabwe, but a recent re-evaluation by Guzmán-Dávalos et al. (2008) supported with ITS sequences indicates a pantropical distribution (Nigeria, Panama) with introductions in Europe (Italy, Switzerland).

Morphologically, the Príncipe specimen is a closer match to the protologue (Berkeley \& Broome 1871) and redescription by Pegler (1986) of G. dilepis (Berk. \& Broome) Singer, which Høiland (1998) reported as occurring in tropical Africa from Nigeria to Kenya, and in tropical Asia from Sri Lanka, the type locality, over Southeast Asia, Borneo and Fiji. He noted that $G$. 
purpureosquamulosus differed from $G$. dilepis in having appressed squamules on the pileus, more deeply decurrent lamellae, a membranous partial veil that forms a persistent annulus, and larger basidiospores with mean $8.2 \times 5.2 \mu \mathrm{m}$ (Høiland 1998). However, the ITS sequence of DED8302 falls in a clade determined as G. purpureosquamulosus by Guzmán-Dávalos et al. (2008), sufficiently distant from a sequence of $G$. dilepis from Malaysia (AY280980). We suspect that this species was reported from São Tomé as Naucoria dilepis by Coutinho (1925), from material growing on palm trunks (Elaeis guineensis).

\section{Hymenogastraceae}

Galerina makereriensis Pegler, Persoonia 4(2): 88. 1966

Figs. 8, 9a-c

Pileus 8-40 $\mathrm{mm}$ diam, convex to broadly convex or seldom campanulate, rarely with a shallow central depression in age, margin pellucid-striate; surface dull, moist to lubricous, glabrous, hygrophanous, disc light brown (6D6-8), margin brownish yellow (5C5-7), fading overall with moisture loss. Context 1-2 mm thick, watery-concolorous. Odor and taste mild. Lamellae horizontal, bluntly adnate, close with 1-2 series of lamellulae, narrow $(-2 \mathrm{~mm})$, brownish yellow to brownish orange (5-6C5-6), brown (6E5-6) in age; spore deposit dark reddish brown (8E-F6-8). Stipe 15-70 × 2-4 mm, central, cylindrical above a subclavate base, hollow; surface dull, dry, longitudinally fibrillose, apex brownish yellow (5C5-6), base dark grayish brown (7F4), base with white tomentum. Partial veil membranous, white, persistent, leaving a superior, striate, off-white annulus 2-4 mm wide.

Basidiospores 7-8.5 $\times 4-5 \mu \mathrm{m}$, amygdaliform, roughened to verruculose, some calyptrate, some with a plage, germ pore absent, thick-walled, rusty brown. Basidia 20-24 × 5.5-6.5 $\mu \mathrm{m}$, clavate, 4-spored. Pleurocystidia and cheilocystidia common, 34-48 $(-56) \times 9.5-12(-15) \mu \mathrm{m}$, ventricose to broadly lageniform, hyaline or seldom with yellow contents, thin-walled. Pileipellis a cutis of hyphae 4-11 $\mu \mathrm{m}$ diam, cylindrical to inflated, hyaline or pale yellowish, non-incrusted, non-gelatinous, thin-walled. Pileus trama interwoven; hyphae 4-16 $\mu \mathrm{m}$ diam, cylindrical to inflated, thin-walled. Lamellar trama subparallel; hyphae similar. Caulocystidia absent. Clamp connections present.

Habitat and known distribution - In cespitose clusters on rotten wood in primary forest. Africa (Kenya, São Tomé, Uganda).

Material examined - Africa, São Tomé island, Macambrara, radio antenna area, $1300 \mathrm{~m}$ elev., N0¹6.557', E0 36.326 ', 25 April 2008, coll. by D.E. Desjardin, DED8325 (SFSU; KX017203); São Tomé island, on trail from Bom Succeso, ca $1300 \mathrm{~m}$ elev., N0 ${ }^{\circ} 17.317^{\prime}$, E6 ${ }^{\circ} 36.746$ ', 2 May 2006, coll. by D.E. Desjardin (material lost).

Notes - Galerina makereriensis was described from Uganda, and is recognized by a medium-sized brownish yellow, glabrous pileus, close, adnate lamellae, a brownish yellow, fibrillose stipe with a persistent, membranous annulus, verruculose and often calyptrate basidiospores, prominent lageniform pleurocystidia and cheilocystidia, clamped hyphae, and growth in cespitose clusters on wood. It was found only at high elevation in primary forests on São Tomé island. No species in GenBank showed $>92 \%$ ITS sequence similarity.

Galerina physospora Singer in Singer and Digilio, Lilloa 25: 381. 1952.

Figs. $9 d-g, 10$ Pileus 10-35 (-40) mm diam, cuspidate to campanulate when young, soon convexpapillate or convex-umbonate, in age broadly convex with or without a central papilla or shallow depression, pellucid-striate; surface dull, moist, glabrous, hygrophanous, disc brown (6-7E6-8) to brownish orange (6C5-7) or brownish yellow (5C5), margin pale brownish orange (6C4-5) or paler, fading to cream (4A3) with moisture loss. Odor and taste indistinct. Lamellae horizontal to ascending, adnate or arcuate, distant with 2 series of lamellulae, moderately broad (2-3 mm), brownish orange (6C4-6). Stipe 10-35 × 1-2 (apex) $\times 2-3$ (base) $\mathrm{mm}$, central to slightly eccentric, terete, cylindrical or gradually enlarged downward, twisted-fibrous, pliant, stuffed to hollow; surface dull, dry, glabrous, lacking veil fibrils at maturity, when young buff overall, soon apex 
grayish orange to brownish orange (5-6B3-5), base brown (6E5-7), in age becoming darker brown (6-7E-F4-8) overall. Partial veil cortinate, fibrils pale orangish white (5A2) to buff or pale grayish orange, evanescent.

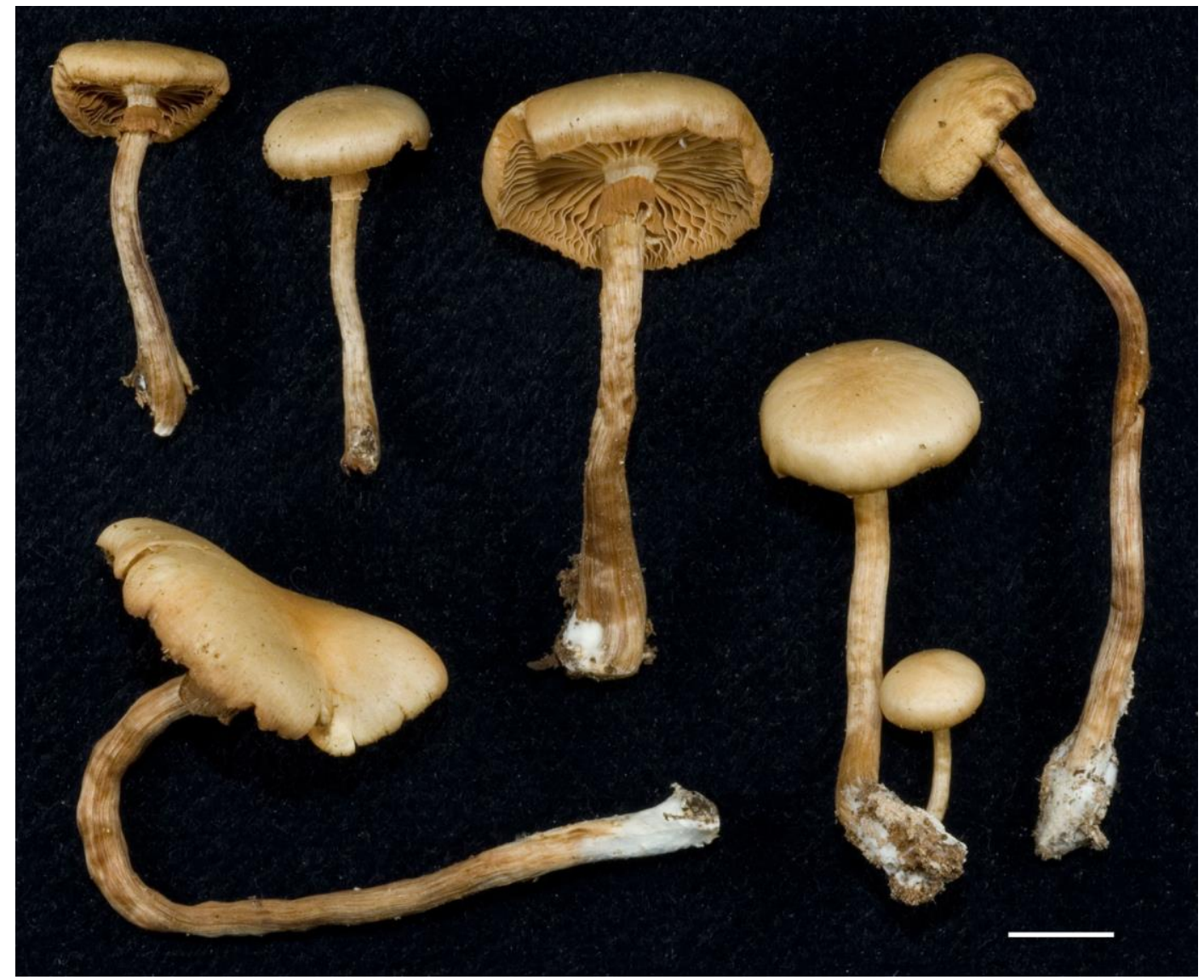

Fig. 8 - Basidiomes of Galerina makereriensis (DED8325). Scale bar $=10 \mathrm{~mm}$.

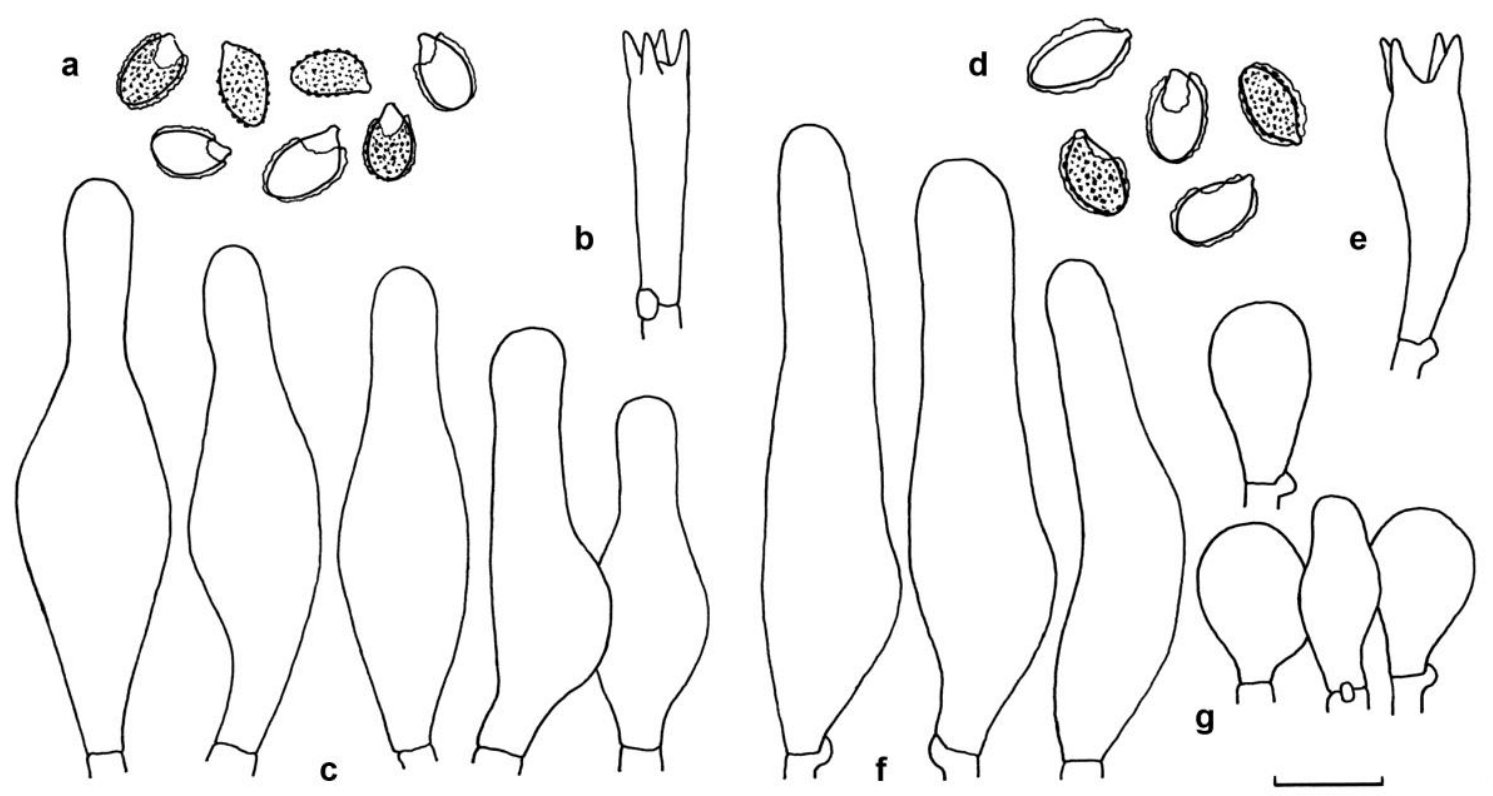

Fig. 9 - Micromorphological features of Galerina makereriensis (a-c; DED8325) and Galerina physospora (d-g; DED8206). a, d. Basidiospores. b, e. Basidia. c, f. Pleurocystidia. g. Cheilocystidia. Scale bar $=10 \mu \mathrm{m}$. 


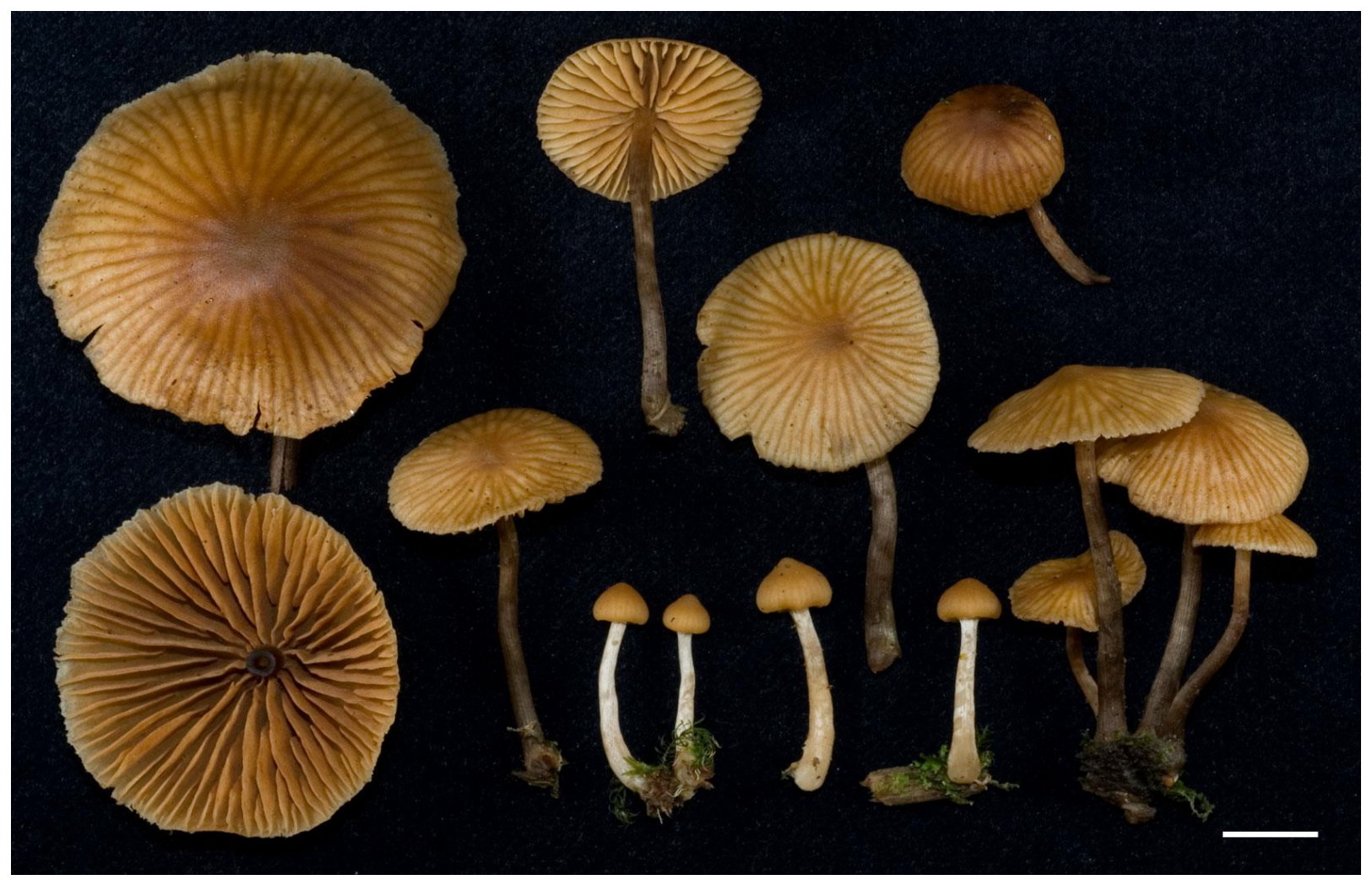

Fig. 10 - Basidiomes of Galerina physospora (DED8206). Scale bar $=10 \mathrm{~mm}$.

Basidiospores 8-9.5 $(-10) \times 4.8-5.2 \mu \mathrm{m}$, amygdaliform, coarsely roughened-verrucose, calyptrate, with a loosened perispore up to $1 \mu \mathrm{m}$ thick (not included in spore measurements), with a distinct smooth plage, rusty brown, dextrinoid. Basidia 24-30 × 6-8 $\mu \mathrm{m}$, clavate, 4-spored. Basidioles subclavate. Pleurocystidia common, 52-80 $\times(9-)$ 10-18 $\mu \mathrm{m}$, clavate to fusoidventricose or lageniform, hyaline, thin-walled. Cheilocystidia abundant, lamellar edge mostly sterile, 13-24 × 7-15 $\mu \mathrm{m}$, broadly clavate to vesiculose, hyaline, thin-walled. Pileipellis a cutis of repent hyphae 4-9 $\mu \mathrm{m}$ diam, cylindrical, smooth or brownish orange-incrusted, non-gelatinous, thin-walled; terminal cells undifferentiated. Pileus and lamella trama interwoven to subparallel, hyphae 4-12 $\mu \mathrm{m}$ diam, smooth, hyaline, non-gelatinous. Caulocystidia absent. Clamp connections present.

Habitat and known distribution - Gregarious on rotten wood of undetermined dicotyledonous trees in primary forests. Africa (São Tomé), Argentina, Hawaiian Islands.

Material examined - Africa, São Tomé island, Macambrara, radio antenna area, $1300 \mathrm{~m}$ elev., N0¹6.557', E0³6.326', 11 April 2008, coll. by D.E. Desjardin, DED8206 (SFSU; KX017204); São Tomé island, Parque Nacional Obo, on trail to Lagoa Amelia, between N0 ${ }^{\circ} 17.112^{\prime}, \mathrm{E}^{\circ} 35.967^{\prime}$ and N0 ${ }^{\circ} 16.922^{\prime}, \mathrm{E}^{\circ} 36.062^{\prime}$, coll. by D.E. Desjardin, DED8242 (SFSU; KX017205).

Notes - Galerina physospora was described originally from Tucuman Province, Argentina (Singer and Digilio 1952), and subsequently reported from the Hawaiian Islands (Horak et al. 1996). Distinctive features include a cuspidate to convex-umbonate, glabrous pileus, dark brown mature stipe, cortinate and evanescent partial veil, coarsely verrucose basidiospores with loosened perispore, relatively small broadly clavate to vesiculose cheilocystidia, large fusoid-ventricose pleurocystidia, and growth on wood in primary forests. The São Tomé material differs from the protologue and Hawaiian specimens only subtly in having a mature stipe that lacks remnants of the partial veil, which are conspicuous as a fibrillose zone near the stipe apex in South American and central Pacific populations. A BLAST search with ITS sequences of DED8206 and DED8242 show closest similarity $(96.8 \%)$ to an undetermined species of Galerina of unknown provenance (HQ827182). 


\section{Psathyrellaceae}

Coprinellus aureogranulatus (Uljé \& Aptroot) Redhead, Vilgalys \& Moncalvo, in Redhead, Vilgalys, Moncalvo, Johnson \& Hopple, Taxon 50(1): 232. 2001.

Figs. 11, 12a-f

Basionym: Coprinus aureogranulatus Uljé \& Aptroot, Persoonia 16(4): 549. 1998.

Pileus 28-50 mm diam, plano-umbonate to depressed with uplifted margin, plicate, translucent; surface on disc with granulose, brown (6E6-8) universal veil remnants, elsewhere glabrous; disc brown to light brown (6D-E5-8), margin grayish brown (6-7E3) to brown (7E4) or paler. Context $<1 \mathrm{~mm}$ thick, concolorous with surface. Lamellae horizontal, adnexed, close to crowded with 2-3 series of lamellulae, relatively narrow $(2-3 \mathrm{~mm})$, brown to dark grayish brown (7E-F4) with hyaline-ciliate edges. Stipe 40-70 × 2-3 mm, central, cylindrical or slightly enlarged downward, terete, fragile, hollow; surface hispid overall, white.

Basidiospores 8-10.5 $\times 5-5.5 \mu \mathrm{m}$, ellipsoid to phaseoliform, smooth, with a broad germ pore, slightly thick-walled, dark brown. Basidia 12.8-16 × 7-9 $\mu \mathrm{m}$, broadly clavate, 4-spored. Pleurocystidia absent. Cheilocystidia common but scattered, 57-85 $\times 14-23 \mu \mathrm{m}$, lageniform to fusoid ventricose with a subcylindrical neck 7-9.5 $\mu \mathrm{m}$ diam, hyaline, thin-walled. Pileipellis a hymeniderm or epithelium with scattered pileocystidia; cells clavate to vesiculose, $16-30 \mu \mathrm{m}$ diam, hyaline, thin-walled; pileocystidia 100-150 × 12-23 $\mu \mathrm{m}$, fusoid with a subcylindrical neck 5.7-9.6 $\mu \mathrm{m}$ diam, neck hyaline, thin-walled, base hyaline to pale brown, thin- or thick-walled. Universal veil cells on pileus disc $22-44 \times 16-30 \mu \mathrm{m}$, globose to vesiculose or broadly clavate, smooth or slightly incrusted, golden brown, thin-walled or with walls up to $1 \mathrm{~mm}$ thick. Stipe cortical and medullary hyphae 4.5-20 $\mu \mathrm{m}$ diam, cylindrical, parallel, smooth, hyaline, thin-walled. Caulocystidia scattered, 75-130 × 12-20 $\mu \mathrm{m}$, narrowly lageniform with a subcylindrical neck 8-9.5 $\mu \mathrm{m}$ diam, hyaline, firm-walled $(-0.5 \mu \mathrm{m})$. Clamp connections absent.

Habitat and known distribution - Solitary, scattered on fallen undetermined dicotyledonous woody debris in coastal secondary forest.

Material examined - Africa, São Tomé island, along main road (EN-1) on north side of island at $18.25 \mathrm{~km}$ marker, Shipwreck Cove, N0²3.687', E6 ${ }^{\circ} 36.302^{\prime}, 17$ April 2008, coll. by D.E. Desjardin, DED8251 (SFSU; KX017206).

Notes - Distinctive features of Coprinellus aureogranulatus include large basidiomes that grow on woody debris, relatively small, ellipsoid basidiospores, lageniform cheilocystidia, pileocystidia and caulocystidia with subcylindrical neck 7-9.5 $\mu \mathrm{m}$ diam, no pleurocystidia, and golden brown, thick-walled, globose velar cells 16-30 $\mu \mathrm{m}$ diam on the pileus disc. The species was described originally from Papua New Guinea (Uljé et al. 1998) and reported as known at the time only from that country. An ITS sequence (GQ249274) of a living culture isolated from soil in a tropical forest, Madang Province, Papua New Guinea (CBS 973.95) matches an ITS sequence from the São Tomé specimen with $99.3 \%$ similarity. Morphologically, the ST specimen differs only subtly from the protologue in forming larger basidiospores $(8-10.5 \times 5-5.5 \mu \mathrm{m}$ v.s. $6.2-7.8 \times 4.1-$ $5.1 \mu \mathrm{m})$ and cheilocystidia with narrower necks $(7-9.5 \mu \mathrm{m}$ v.s. $8-16 \mu \mathrm{m})$.

Pegler (1986) reported $C$. hiascens from Sri Lanka and that material matches closely the São Tomé specimen of $C$. aureogranulatus, except for its habit of growing among grasses. European material of $C$. hiascens differs in forming hyaline, cylindrical to inflated velar cells only 2-15 $\mu \mathrm{m}$ diam, smaller cheilocystidia, longer pileocystidia (up to $250 \mu \mathrm{m}$ ) with a tapering neck, and growth in grasslands (Uljé 2005). Coprinellus aureogranulatus fits in the traditional Coprinus sect. Pseudocoprinus subsect. Setulosi, where it shows affinities to Coprinellus ephemerus (Bull.) Redhead, Vilgalys \& Moncalvo, and C. subimpatiens (M. Lange \& A.H. Sm.) Redhead, Vilgalys \& Moncalvo, reported from East Africa (Pegler 1977). Coprinellus ephemerus differs in forming larger basidiospores $(11-16 \times 6-8 \mu \mathrm{m})$, vesiculose to globose cheilocystidia, distinctive pleurocystidia, and grows on dung and straw (Pegler 1977, Uljé 2005). Coprinellus subimpatiens differs in forming larger basidiospores $(9.5-14 \times 5-8 \mu \mathrm{m})$, subglobose to lageniform cheilocystidia (-50 $\mu \mathrm{m}$ diam), often has pleurocystidia, and grows in soil (Pegler 1977, Uljé 2005). 


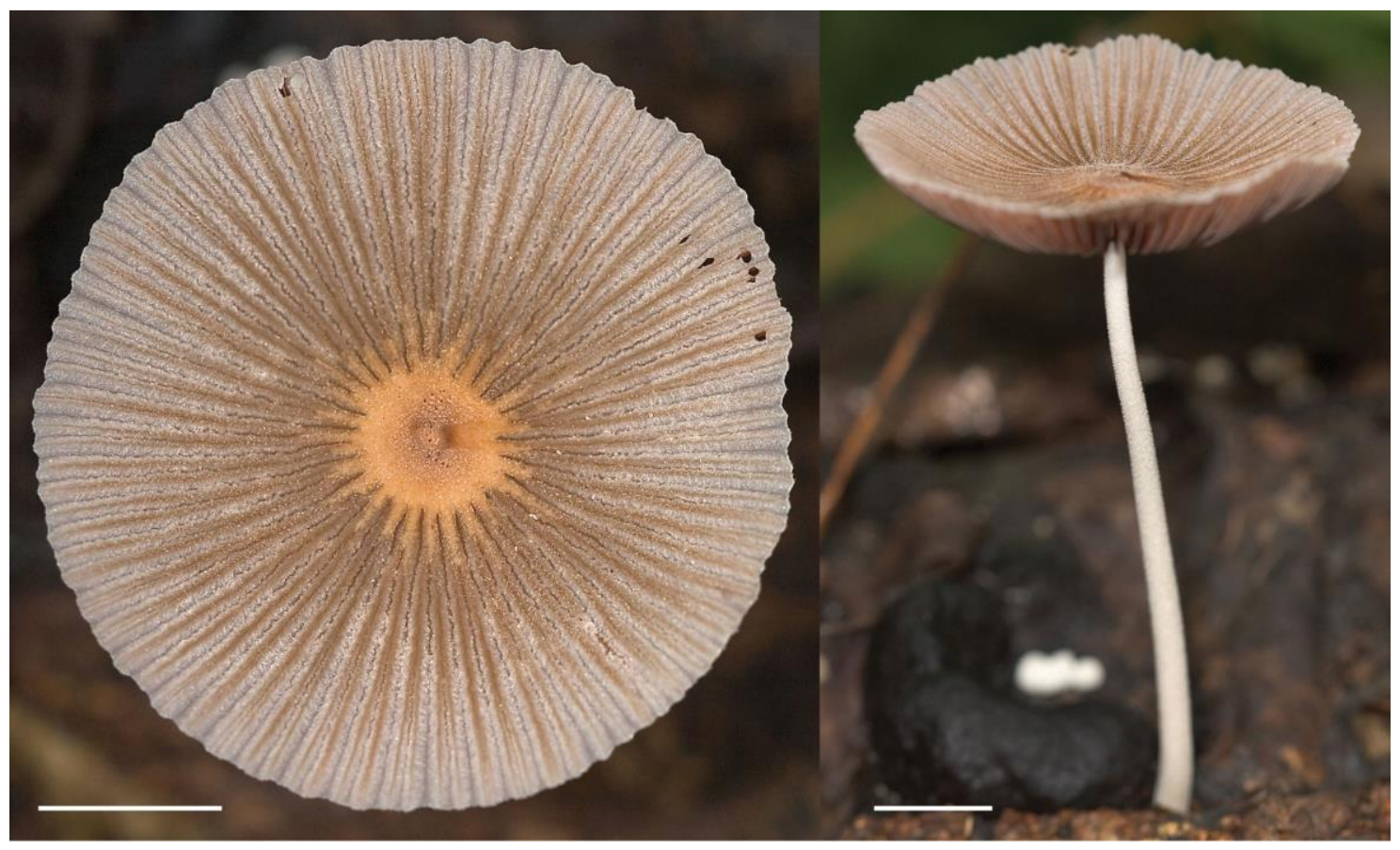

Fig. 11 - Basidiomes of Coprinellus aureogranulatus (DED8251). Scale bar $=10 \mathrm{~mm}$.

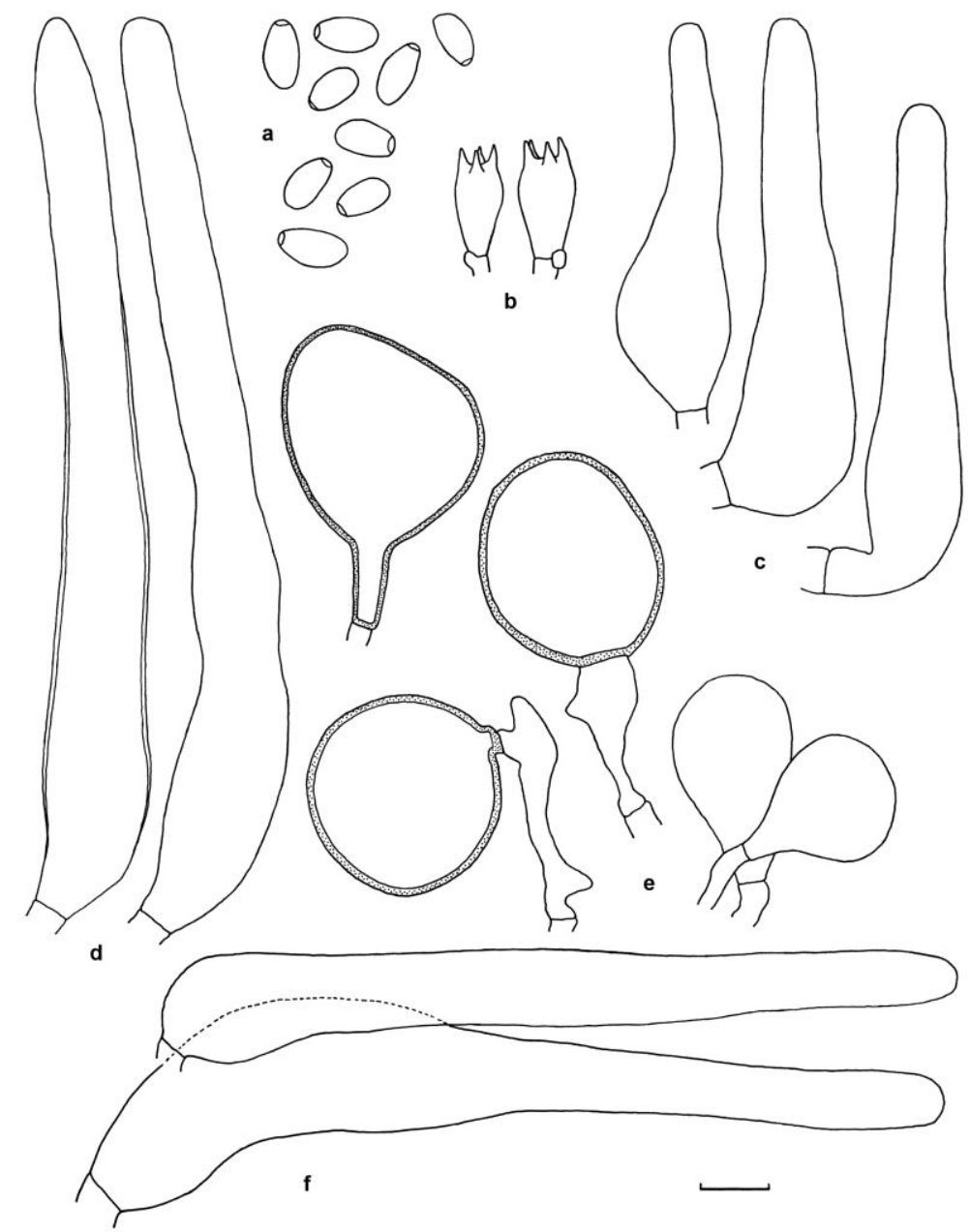

Fig. 12 - Micromorphological features of Coprinellus aureogranulatus (DED8251). a. Basidiospores. b. Basidia. c. Cheilocystidia. d. Pileocystidia. e. Universal veil cells. f. Caulocystidia. Scale bar $=10 \mu \mathrm{m}$ 
Coprinellus disseminatus (Pers.) J.E. Lange, Dansk. Bot. Ark. 9(6): 93. 1938.

Basionym: Agaricus disseminatus Pers., Syn. Meth. Fung. (Göttingen) 2: 403. 1801.

$=$ Coprinus disseminatus (Pers.) Gray, Nat. Arr. Brit. Pl. (London) 1: 634. 1821.

= Coprinarius disseminatus (Pers.) P. Kumm., Führ. Pilzk. (Zerbst): 68. 1871.

= Psathyrella disseminata (Pers.) Quél., Mém. Soc. Émul. Montbéliard, Sér. 2 5: 123. 1872.

= Pseudocoprinus disseminatus (Pers.) Kühner, Botaniste 20: 156. 1928.

Habitat and known distribution - Densely gregarious in woody debris-laden soil in primary forests. Cosmopolitan.

Material examined - Africa, São Tomé island, along aqueduct trail at Rio Contador, elev. 600 m, N0 $18.7844^{\prime}, E^{\circ} 37.151^{\prime}, 30$ April 2006, coll. by D.E. Desjardin, DED7985 (material lost in transit); São Tomé island, Parque Nacional Obo, trail to Lagoa Amelia, between $\mathrm{N0}^{\circ} 17.112^{\prime}$, E6 ${ }^{\circ} 35.967^{\prime}$ and $\mathrm{N0}^{\circ} 16.922^{\prime}, \mathrm{E}^{\circ} 36.062^{\prime}, 14$ April 2008, coll. by B.A. Perry, BAP608 (SFSU; KX017207).

Notes - This is a well known species reported from São Tomé by Bresadola and Roumeguère (1890 - as Psathyrella disseminata) and Coutinho (1925 - as Coprinarius disseminatus). For a description of African material refer to Pegler (1977). An ITS sequence of BAP608 shows $>99.5 \%$ similarity with several GenBank sequences of $C$. disseminatus (KJ780770 from Malaysia, KC771476 from Ecuador).

Coprinopsis afronivea Desjardin \& B.A. Perry, sp. nov.

Figs. 13, 14a-d MycoBank MB 816219

Diagnosis - Pileus 9-18 mm diam, campanulate to obtusely conical, white to pale grayish white, covered with white to yellowish white micaceous granules. Lamellae adnexed, close, initially gray, becoming dark gray to black. Stipe $25-40 \times 1-2 \mathrm{~mm}$, cylindrical, covered with sparse, white tomentum, white. Basidiospores 8.5-9.6 × 6.4-7.0 $\mu \mathrm{m}$ (face) $\times 5.5-6.2 \mu \mathrm{m}$ (profile), mitriform in face view, ellipsoid to amygdaliform in profile, smooth, with a prominent germ pore, black. Pleurocystidia absent. Cheilocystidia globose to broadly clavate, $12-17 \mathrm{~mm}$ diam. Pileipellis an epithelium of globose cells $16-40 \mu \mathrm{m}$ diam. Universal veil cells $16-40 \times 16-34 \mu \mathrm{m}$, vesiculose, smooth, rarely a few with several knobby outgrowths. On roots and woody debris of baobab trees. Holotype: Africa, São Tomé island, along main road (EN-1) on north side of island near $16.5 \mathrm{~km}$ marker, 17 April 2008, B.A. Perry, BAP619 (SFSU; KX017208).

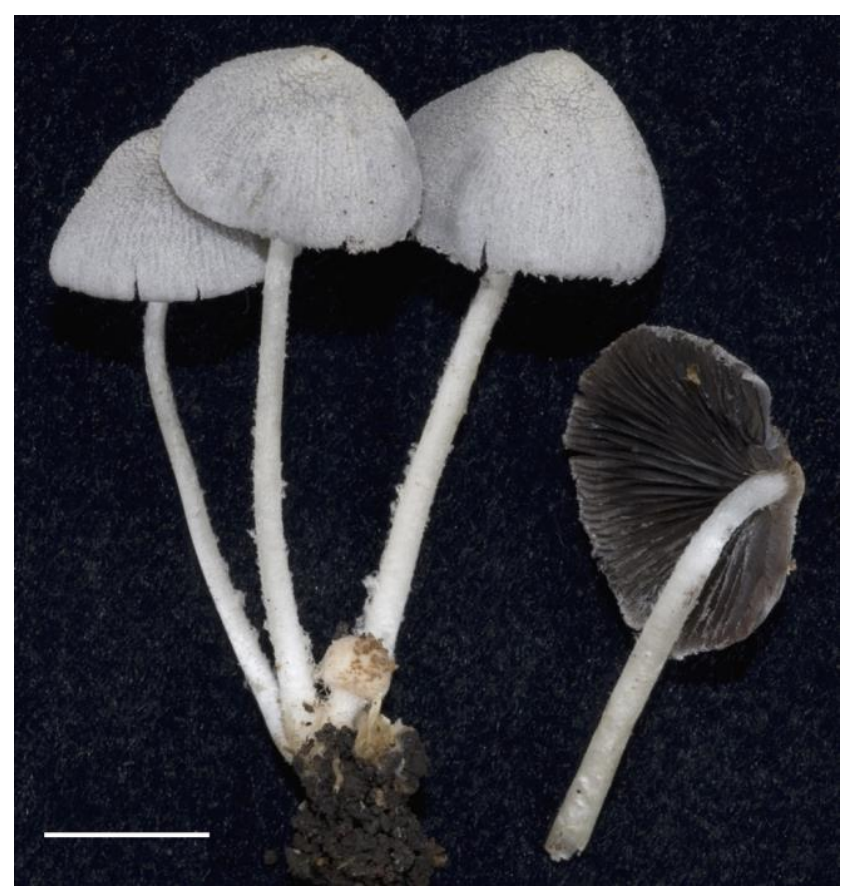

Fig. 13 - Basidiomes of Coprinopsis afronivea (Holotype, BAP619). Scale bar = $10 \mathrm{~mm}$. 

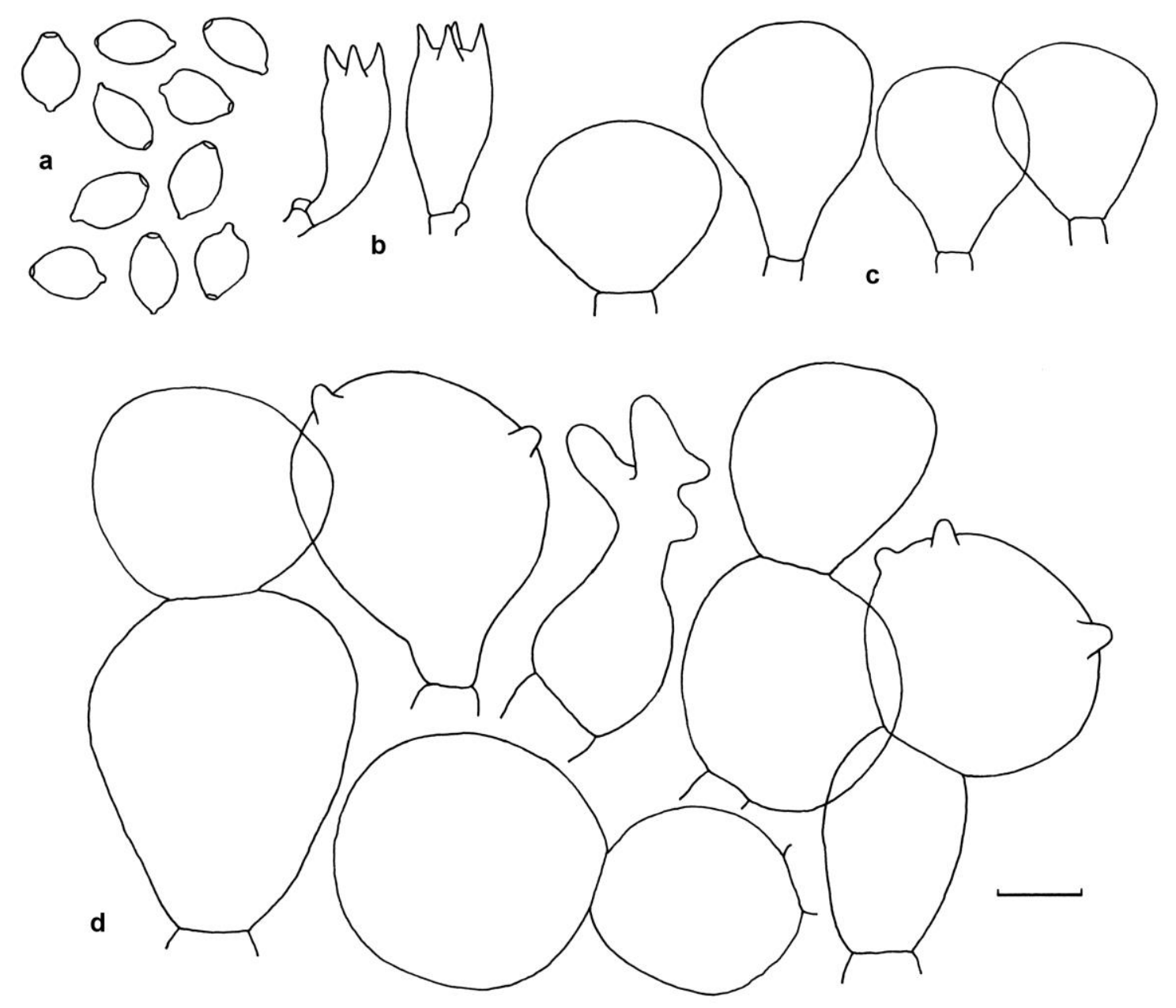

Fig. 14 - Micromorphological features of Coprinopsis afronivea (Holotype, BAP619). a. Basidiospores. b. Basidia. c. Cheilocystidia. d. Universal veil cells. Scale bar $=10 \mu \mathrm{m}$

Etymology - afro $=$ Africa; nivea $=$ snowy - referring to a snow white African species similar to Coprinopsis nivea.

Pileus 9-18 mm diam, campanulate to obtusely conical, margin faintly striatulate, splitting in age; surface covered with dense, white to yellowish white (4A2), micaceous universal veil granules, ground color pale grayish white. Context $<1 \mathrm{~mm}$ thick, white. Odor fungal. Lamellae ascending, adnexed, close with 1-2 series of lamellulae, narrow, initially gray, becoming dark gray to black. Stipe $25-40 \times 1-2 \mathrm{~mm}$, central, cylindrical or slightly enlarged downward, terete, hollow; surface dull, dry, covered with sparse, white tomentum, ground color and context white.

Basidiospores 8.5-9.6 $\times 6.4-7.0 \mu \mathrm{m}$ (face) $\times 5.5-6.2 \mu \mathrm{m}$ (profile), mitriform in face view, ellipsoid to amygdaliform in profile, smooth, with a prominent germ pore and apiculus, thickwalled, black. Basidia 16-20 × 8-10 $\mu \mathrm{m}$, broadly clavate, 4-spored. Pleurocystidia absent. Cheilocystidia scattered, 20-29 × 12-24 $\mu \mathrm{m}$, globose to broadly clavate, hyaline, thin-walled, readily collapsed (few observed due to maturation). Pileipellis an epithelium of globose cells 16-40 $\mu \mathrm{m}$ diam, hyaline, thin-walled. Universal veil cells $16-40 \times 16-34 \mu \mathrm{m}$, vesiculose, smooth, rarely a few with several knobby outgrowths, hyaline to pale yellow, thin-walled. Caulocystidia absent. Clamp connections present.

Habitat and known distribution - Subcespitose on epigeous roots of baobab and woody debris under baobab trees. Africa (São Tomé).

Material examined - Africa, São Tomé island, along main road (EN-1) on north side of island near $16.5 \mathrm{~km}$ marker, N0²4.374', E6 37.092', 17 April 2008, coll. by B.A. Perry and D.E. Desjardin, BAP619 (Holotype, SFSU; KX017208). 
Notes - Coprinopsis afronivea is characterized by rather small, white basidiomes, a pileus covered with white to yellowish white micaceous granules, a white tomentose stipe, moderatelysized basidiospores mitriform in face view with a prominent germ pore, globose cheilocystidia, no pleurocystidia, vesiculose universal veil cells, and growth on baobab roots and woody debris. In historical taxonomic schemes, Coprinopsis afronivea belongs in Sect. Veliformes, Subsect. Nivei where it shows similarities to Coprinus cardiasporus Bender, but the latter has smaller basidiospores $(5.5-8.5 \times 5.0-6.5 \times 3.5-4.5 \mu \mathrm{m})$, distinctive pleurocystidia, and smaller basidiomes formed on dung or compost heaps (Uljé 2005). The São Tomé taxon would key to East African material of Coprinellus micaceus (Bull.) Vilgalys, Hopple \& Jacq. Johnson as reported by Pegler (1977), but the latter forms much larger basidiomes with ochraceous to yellow-ferruginous pileus 30-60 mm diam, distinctive pleurocystidia and more conspicuous cheilocystidia. An ITS sequence of BAP619 shows 94.9-95.2\% similarity to several GenBank sequences of Coprinopsis nivea (Pers.) Redhead, Vilgalys \& Moncalvo. The latter differs in forming larger basidiomes with larger basidiospores $(12-19 \times 11-15.5 \times 7.5-9 \mu \mathrm{m})$, distinct pleurocystidia, larger cheilocystidia $(15-50$ $\mu \mathrm{m}$ broad), and growth on dung (Uljé 2005).

Coprinopsis cinerea (Schaeff.) Redhead, Vilgalys \& Moncalvo, in Redhead, Vilgalys, Moncalvo, Johnson \& Hopple, Taxon 50(1): 227. 2001.

Basionym: Agaricus cinereus Schaeff., Fung. Bavar. Palat. Nasc. (Ratisbonae) 4: 100. 1774. $=$ Coprinus cinereus (Schaeff.) Gray, Nat. Arr. Britl Pl. (London) 1: 634. 1821.

Notes - Coprinopsis cinerea was reported from São Tomé by Saccardo and Berlese (1889; as Coprinus cinereus) with the following notes: "ad Nova Moka altit $800 \mathrm{~m}$. Sporae obovatae, 12 $14 \times 6-7 \mu \mathrm{m}$, atro-fuligineae. A. Moller." We have not encountered this species on São Tomé or Príncipe.

Psathyrella albipes (Murrill) A.H. Sm., Mem. N. Y. Bot. Gdn. 24: 283. 1972. Figs. 15, 16a-c Basionym: Astylospora albipes Murrill, Mycologia 10: 22. 1918 (ut Atylospora albipes).

= Psathyra albipes (Murrill) Murrill, Mycologia 10: 33. 1918.

Pileus 4-10 mm diam, convex to broadly convex, margin incurved to recurved, pellucidstriate; surface moist, dull, glabrous, smooth, hygrophanous, at first white, soon pale grayish orange (5B2) to pale gray, becoming dingy white with moisture loss, mostly appearing off-white overall; drying pale cream-brown. Context $<1 \mathrm{~mm}$ thick, white. Odor none. Lamellae horizontal, adnate, close with 3 series of lamellulae, moderately broad ( $-2 \mathrm{~mm}$ ), pale grayish brown (6D3). Stipe 15$30 \times 1-1.5 \mathrm{~mm}$, central, cylindrical, terete, hollow, brittle; surface shiny, silky-glabrous, white. Partial veil a cortina of white fibrils, a few hanging on the pileus margin, soon evanescent.

Basidiospores 6-7 $\times$ 4.5-5 $\mu \mathrm{m}$, ellipsoid, smooth, with a prominent germ pore, thickwalled, dark grayish brown. Basidia 15-17 × 7.5-8 $\mu \mathrm{m}$, clavate, 4-spored, clamped. Pleurocystidia absent. Cheilocystidia abundant, lamellar edge sterile; 19-24 × 9-13.5 $\mu \mathrm{m}$, broadly clavate, hyaline, thin-walled to firm-walled $(<0.5 \mu \mathrm{m})$. Pileipellis an epithelium of globose cells $10-30 \mu \mathrm{m}$ diam, hyaline, thin-walled; velar cells, pileocystidia and setae absent. Stipe cortical hyphae 3-8 $\mu \mathrm{m}$ diam, cylindrical, hyaline. Caulocystidia absent. Clamp connections common in all tissues.

Habitat and known distribution - Densely gregarious on wood of canopy trees in a coastal coconut-banana grove. Africa (São Tomé), Jamaica.

Material examined - Africa, São Tomé island, along main road (EN-1) on west side of island near $45 \mathrm{~km}$ marker, N0 ${ }^{\circ} 13.914^{\prime}, \mathrm{E}^{\circ} 28.671^{\prime}, 27$ April 2008, col. by D.E. Desjardin, DED8340 (SFSU; KX017209).

Notes - Psathyrella albipes is distinguished by small, white to pale grayish orange pileus, a shiny white, silky-glabrous stipe lacking caulocystidia, an evanescent, fibrillose partial veil, small basidiospores, no pleurocystidia, broadly clavate cheilocystidia, and lignicolous habit. Originally described from Jamaica where it was collected on a decayed banana stalk, the protologue differs only subtly from the São Tomé material in forming slightly narrower basidiospores $(4-4.2 \mu \mathrm{m})$ and a pileus described as "finely asperulate, pale avellaneous" (Murrill 1918). 


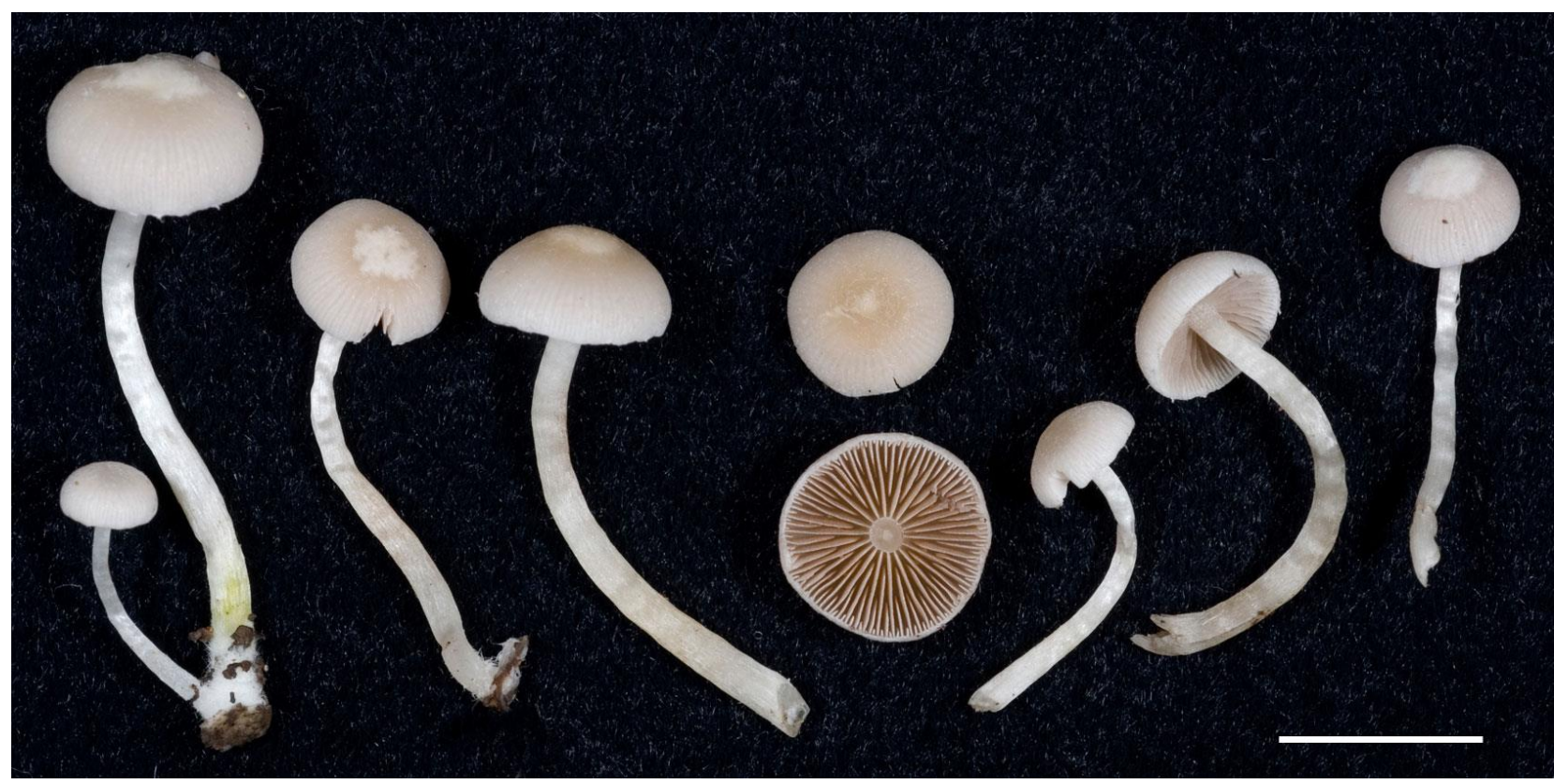

Fig.15 - Basidiomes of Psathyrella albipes (DED8340). Scale bar $=10 \mathrm{~mm}$.
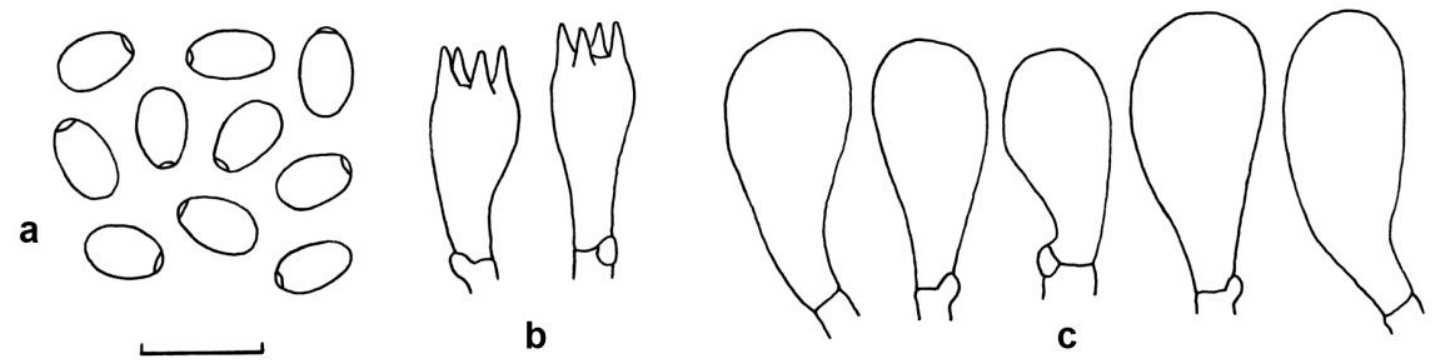

Fig. 16 - Micromorphological features of Psathyrella albipes (DED8340). a. Basidiospores. b. Basidia. c. Cheilocystidia. Scale bar $=10 \mu \mathrm{m}$.

In the taxonomy of Smith (1972), Psathyrella albipes belongs in subgen. Psathyrella, sect. Subatratae, ser. Atricastaneae where it shows similarities to several poorly documented species also described from the Caribbean, viz., P. byssina (Murrill) A.H. Sm., and P. roystoniae (Earle) A.H. Sm. Psathyrella byssina has a pinkish gray to brown pileus tinged with pink, a pallid or rosyisabelline stipe attached to the substrate by a conspicuous tomentose matt, and lacks a veil. Psathyrella roystoniae forms a larger $(10-30 \mathrm{~mm})$, reticulate to striatulate pileus tinged with purple, slightly longer basidiospores (7-8 $\mu \mathrm{m})$, and grows on Roystonea palms.

In the taxonomy of Kits Van Waveren (1985), Psathyrella albipes belongs in subgen. Psathyra, sect. Spintrigerae where it shows affinities to P. lacuum Huijsman, a species described from material collected in the Netherlands on the wooden handle of a brush partially submerged in water. The latter species differs only subtly in pileus color (pink), lamellar color (pale grayish lilac), a white-flocculose stipe surface, and substrate; micromorphology is indistinguishable.

Psathyrella albipes shows some similarities to P. glaucescens Dennis, described from Venezuela and reported from East Africa (Pegler 1977), but the latter species forms larger (15-50 $\mathrm{mm})$, olivaceous buff pileus, narrower basidiospores (3.7-4.5 $\mu \mathrm{m})$, and larger cheilocystidia (25-40 $\times 13-20 \mu \mathrm{m})$. Psathyrella efflorescens (Berk. \& Broome) Pegler differs in forming pinkish gray to purplish brown pileus that turns black when dried, has slightly smaller cheilocystidia $(12-18 \times 7.5-$ $14 \mu \mathrm{m})$, pale yellowish brown basidiospores and lacks a veil (Pegler 1977, 1986). 
Diagnosis - Pileus 5-15 mm diam, convex to broadly convex, glabrous, hygrophanous, brown to dark brown, fading to pale brownish gray or grayish white. Lamellae adnexed to shallowly adnate, close, pale brownish gray to dark brown. Stipe $15-40 \times 1-2 \mathrm{~mm}$, cylindrical, pruinose to silky-glabrous above, base pubescent, white. Partial veil absent. Basidiospores 5.7-6.8 $\times 3.5-4.5(-4.8) \mu \mathrm{m}$, ellipsoid or slightly bean-shaped in profile, smooth, lacking a germ pore, grayish brown. Basidia 16.5-20 × 8.5-9 $\mu \mathrm{m}$, clavate, 4-spored. Pleurocystidia absent. Cheilocystidia 16.5-29 $\times 8-12 \mu \mathrm{m}$, ventricose to broadly lageniform. Pileipellis an epithelium of globose to vesiculose cells $16-32 \mu \mathrm{m}$ diam; velar cells, pileocystidia and setae absent. Caulocystidia common, 20-52 × (5-) 9.5-14.5 $\mu \mathrm{m}$, cylindrical to clavate or lageniform. Clamp connections common in all tissues. Gregarious on rotten wood and banana debris in coastal cacaobanana grove. Holotype: Africa, São Tomé, along main road (EN-1) on west side of island near 33 km marker, 27 April 2008, D.E. Desjardin, DED8339 (SFSU; KX017210).

Etymology - cacao $=$ chocolate; referring to both the color of the fresh pileus, like milk chocolate, and its association with cacao trees.

Pileus 5-15 mm diam, convex to broadly convex, becoming plano-convex to nearly plane, margin in age striatulate, sometimes cleft or lobed; surface glabrous, dull, moist, hygrophanous, at first grayish brown (6-8D-E3-4) overall or with a brown to dark brown (7E-F6-7) central spot, in age disc becoming light brown (6D4), elsewhere pale brownish gray (5-6C-D3) to grayish orange (6B3), fading to grayish white or nearly white with moisture loss. Context $<1 \mathrm{~mm}$ thick, white or watery-concolorous. Odor indistinct. Lamellae horizontal to ascending, adnexed to shallowly adnate, close with 2 series of lamellulae, narrow (1-2 mm), initially pale brownish gray (6C3), becoming brown (7D4) to dark brown (7E-F4-5). Stipe 15-40 × 1-2 mm, central, cylindrical, terete, hollow, brittle; surface dull, pruinose to silky-glabrous above, base pubescent, white. Partial veil absent.

Basidiospores 5.7-6.8 × 3.5-4.5 (-4.8) $\mu \mathrm{m}$, ellipsoid or slightly bean-shaped in profile, smooth, lacking a germ pore, thin-walled, grayish brown. Basidia 16.5-20 × 8.5-9 $\mu \mathrm{m}$, clavate, 4spored, clamped. Pleurocystidia absent. Cheilocystidia abundant, lamellar edge sterile; 16.5-29 $\times$ 8-12 $\mu \mathrm{m}$, ventricose to broadly lageniform, hyaline, thin-walled. Pileipellis an epithelium of globose to vesiculose cells 16-32 $\mu \mathrm{m}$ diam, hyaline to pale brown, thin-walled; velar cells, pileocystidia and setae absent. Stipe cortical hyphae 4.5-12 $\mu \mathrm{m}$ diam, cylindrical, hyaline. Caulocystidia scattered, common, 20-52 × (5-) 9.5-14.5 $\mu \mathrm{m}$, cylindrical to clavate or lageniform, a few subcapitate, hyaline, thin-walled to firm-walled $(-0.5 \mu \mathrm{m})$. Clamp connections common in all tissues.

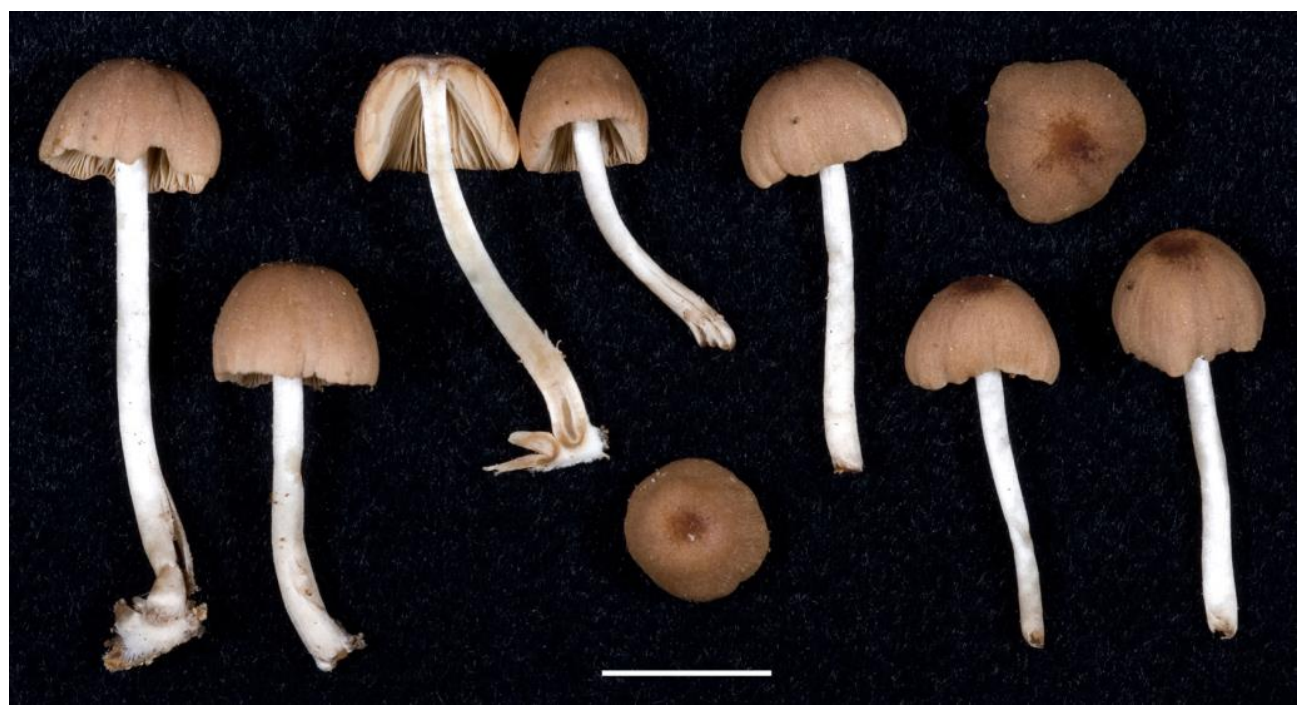

Fig. 17 - Basidiomes of Psathyrella cacao (Holotype, DED8339). Scale bar $=10 \mathrm{~mm}$. 


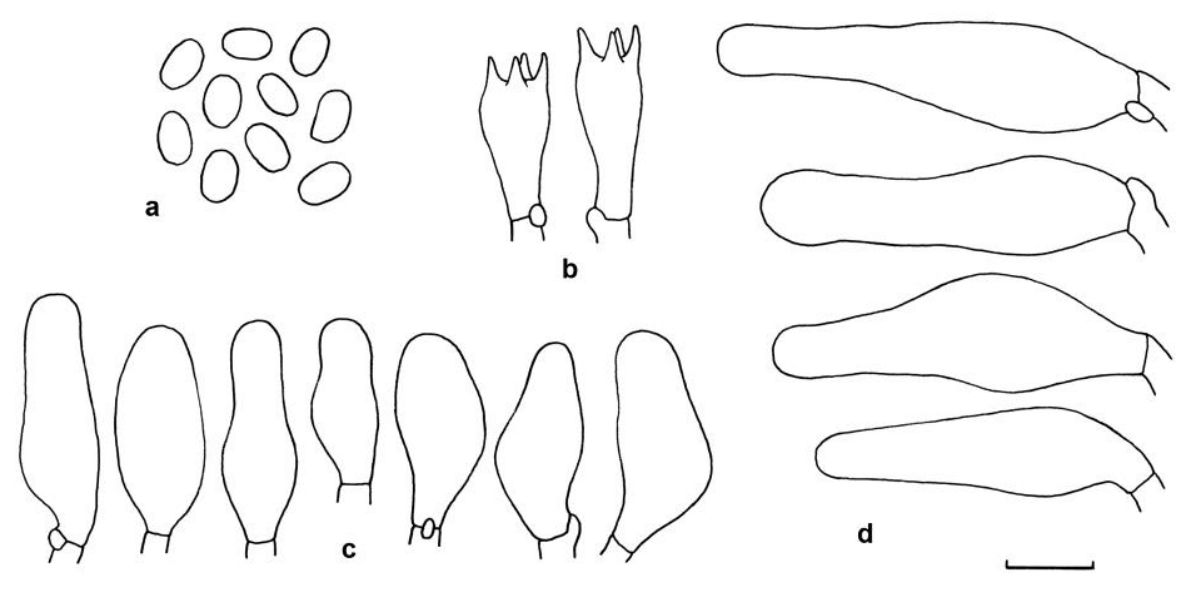

Fig. 18 - Micromorphological features of Psathyrella cacao (Holotype, DED8339). a. Basidiospores. b. Basidia. c. Cheilocystidia. d. Caulocystidia. Scale bar $=10 \mu \mathrm{m}$.

Habitat and known distribution - Gregarious on rotten wood and banana debris in coastal cacao-banana grove. Africa (São Tomé).

Material examined - Africa, São Tomé island, along main road (EN-1) on west side of island near $33 \mathrm{~km}$ marker, N0¹9.607', E6 30.666', 27 April 2008, coll. by D.E. Desjardin, DED8339 (Holotype, SFSU; KX017210); same location, 18 April 2008, coll. by D.E. Desjardin, DED8262 (SFSU).

Notes - Psathyrella cacao is characterized by small basidiomes with a convex pileus with brown disc and grayish orange margin, lack of a veil, a white, pruinose stipe, small ellipsoid basidiospores without a germ pore, ventricose to broadly lageniform cheilocystidia, no pleurocystidia, versiform caulocystidia, and growth on woody or banana debris.

In the taxonomy of Smith (1972), Psathyrella cacao belongs in subgen. Psathyrella, sect. Subatratae, ser. Atricastaneae where it shows affinities to P. cordobaensis A.H. Sm. and P. plana (Murrill) A.H. Sm. Psathyrella cordobaensis was described from Mexico with an avellaneousisabelline pileus about $10 \mathrm{~mm}$ diam that is sometimes pitted or reticulate, arcuate and white to pale avellaneous young lamellae, a short, glabrous white stipe lacking caulocystidia, small basidiospores $(6-7.5 \times 3.8-4.4 \mu \mathrm{m})$ with an indistinct germ pore, saccate to ellipsoid cheilocystidia $(22-30 \times 9-$ $12 \mu \mathrm{m}$ ), and growth on decayed wood (Smith 1972, nom. nov. for Astylospora mexicana Murrill). Psathyrella plana, described from Jamaica is similar, but has a glabrous stipe putatively lacking caulocystidia, narrower basidia $(6-7 \mu \mathrm{m})$, larger cheilocystidia $(32-44 \times 10-20 \mu \mathrm{m})$, and basidiospores with an apical germ pore (Smith 1972). An ITS sequence of DED8339 showed 98.098.3\% similarity with three undetermined Psathyrella species sequences (KP686450, KP686452, KT188611) from India.

Psathyrella oboensis Desjardin \& B.A. Perry, sp. nov.

Figs. 19, 20a-d MycoBank MB 816221

Diagnosis - Pileus 7-18 $\mathrm{mm}$ diam, campanulate to obtusely conical, margin smooth, glabrous, dark brown fading to brown. Lamellae shallowly adnate, crowded, narrow, dark brown. Stipe 20-48 × 1-2 mm, cylindrical, glabrous, dingy buff. Partial veil absent. Basidiospores 5-6 $\times$ 3.2-3.5 $\mu \mathrm{m}$, ellipsoid, truncate, smooth, with a prominent germ pore, dark brown to nearly black. Basidia 12.5-16 × 4.8-6 $\mu \mathrm{m}, 4$-spored. Pleurocystidia common, 18-28 $\times$ 7.5-9.5 $\mu \mathrm{m}$, clavatemucronate to ventricose. Cheilocystidia abundant, 9.5-24 × 8-13 $\mu \mathrm{m}$, subglobose to broadly clavate, often catenulate. Pileipellis an epithelium of globose to ovoid cells 20-32 (-44) $\mu \mathrm{m}$ diam; velar cells, pileocystidia and setae absent. Caulocystidia absent. Densely gregarious in thin soil over very rotten wood. Holotype: Africa, São Tomé, Parque Nacional Obo, trail to Lagoa Amelia, 14 April 2008, D.E. Desjardin, DED8234 (SFSU; KX017211). 


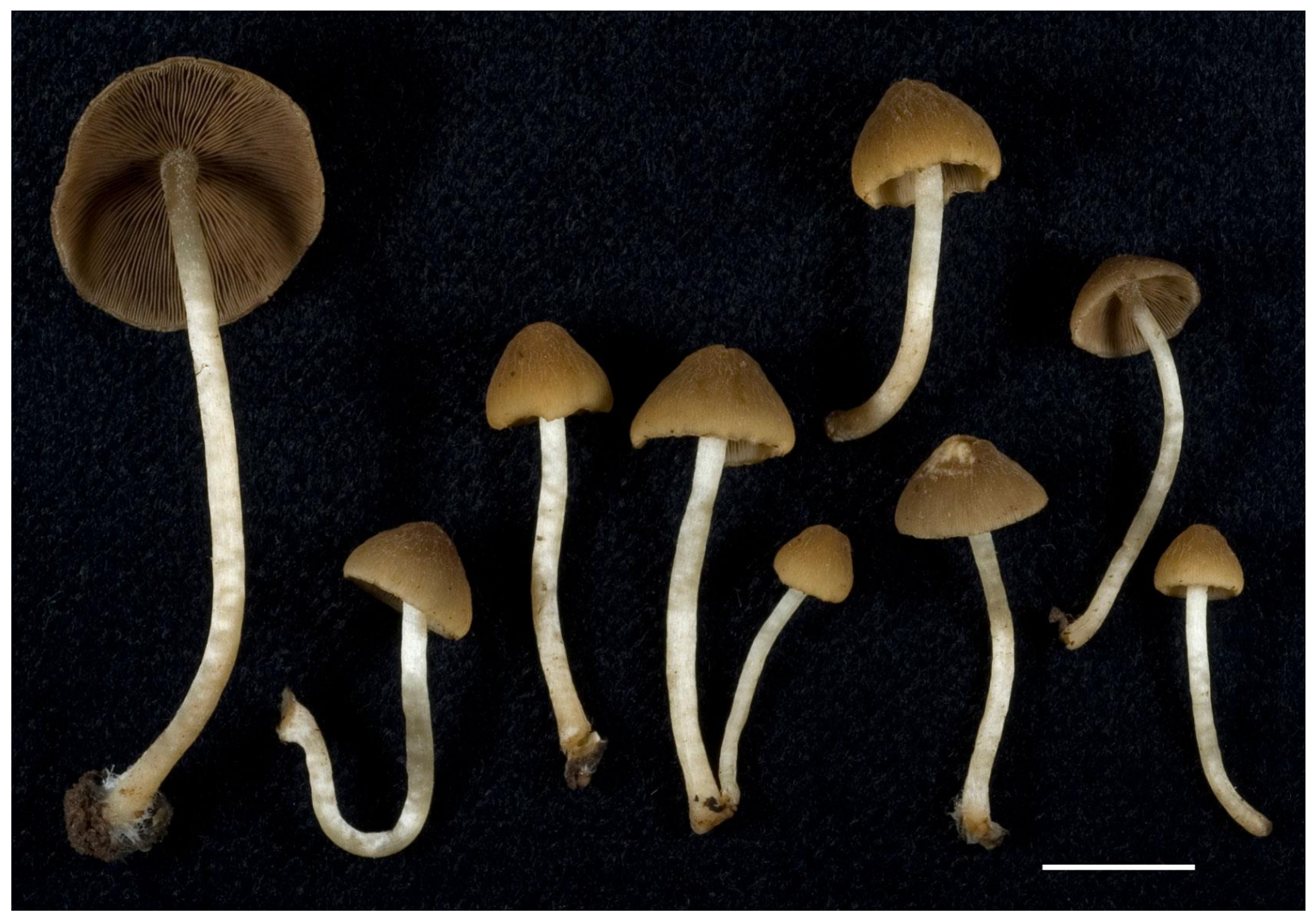

Fig. 19 - Basidiomes of Psathyrella oboensis (Holotype, DED8234). Scale bar = $10 \mathrm{~mm}$.
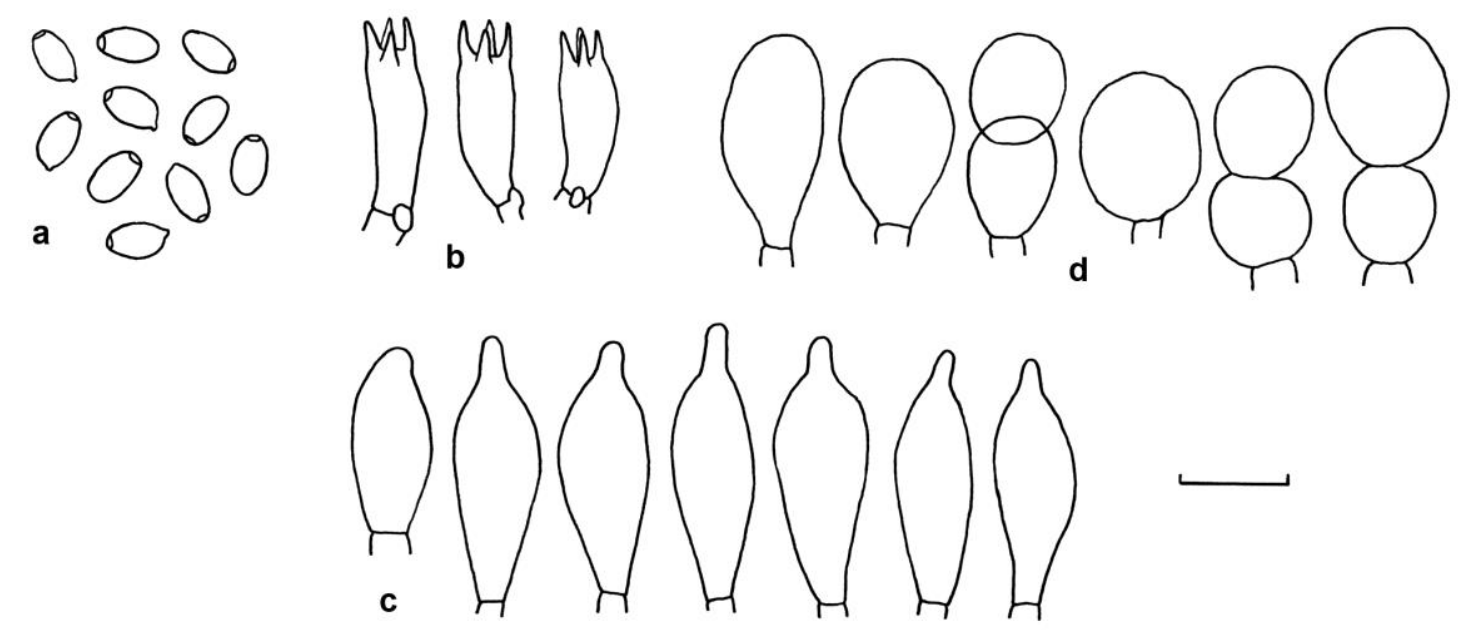

Fig. 20 - Micromorphological features of Psathyrella oboensis (Holotype, DED8234). a. Basidiospores. b. Basidia. c. Pleurocystidia. d. Cheilocystidia. Scale bar $=10 \mu \mathrm{m}$.

Etymology - oboensis - referring to its growth in Parque Nacional Obo.

Pileus 7-18 mm diam, campanulate to obtusely conical, margin smooth (not striate); surface glabrous, dull, moist, hygrophanous, dark brown (7F6-8) overall when young, fading to brown (7E6-8) or light brown (7D6-8) in age and with moisture loss. Context $0.5-1 \mathrm{~mm}$ thick, waterybrown. Odor indistinct. Lamellae horizontal to ascending, shallowly adnate, crowded with 2-3 series of lamellulae, narrow $(<1 \mathrm{~mm})$, dark brown (8F4-5). Stipe 20-48 $\times 1-2 \mathrm{~mm}$, central, cylindrical, terete, solid, brittle; surface subshiny, glabrous, dingy buff. Partial veil absent. 
Basidiospores 5-6 $\times 3.2-3.5 \mu \mathrm{m}$, ellipsoid, truncate, smooth, with a prominent germ pore, thick-walled, dark brown to nearly black. Basidia 12.5-16 × 4.8-6 $\mu \mathrm{m}$, clavate, 4-spored, clamped. Pleurocystidia common, $18-28 \times 7.5-9.5 \mu \mathrm{m}$, clavate-mucronate to ventricose, rarely clavate, hyaline, thin-walled. Cheilocystidia abundant, lamellar edge sterile; 9.5-24 × 8-13 $\mu \mathrm{m}$, subglobose to broadly clavate, often catenulate, hyaline to pale brown (pigment parietal), thin-walled. Pileipellis an epithelium of globose to ovoid cells 20-32 (-44) $\mu$ m diam, hyaline, thin-walled; velar cells, pileocystidia and setae absent. Stipe cortical and medullary hyphae 6-14 $\mu \mathrm{m}$ diam, parallel, cylindrical, hyaline, thin-walled. Caulocystidia absent. Clamp connections common in all tissues.

Habitat and known distribution - Densely gregarious in thin soil over very rotten wood in primary forest. Africa (São Tomé).

Material examined - Africa, São Tomé island, Parque Nacional Obo, trail to Lagoa Amelia, between N0 ${ }^{\circ} 17.112^{\prime}, \mathrm{E}^{\circ} 35.967^{\prime}$ and $\mathrm{N0}^{\circ} 16.922^{\prime}, \mathrm{E}^{\circ} 36.062^{\prime}, 14$ April 2008, coll. by D.E. Desjardin, DED8234 (SFSU; KX017211).

Notes - Distinctive features of Psathyrella oboensis include a small, conical, glabrous, dark brown hygrophanous pileus, very crowded and narrow lamellae, a buff, glabrous stipe lacking a partial veil, very small basidiospores with a prominent germ pore, mucronate pleurocystidia, broadly clavate to subglobose cheilocystidia, no caulocystidia, and growth on buried rotten wood. In the taxonomy of Smith (1972), P. oboensis belongs in subgen. Psathyrella, sect. Obtusatae, subsect. Obtusatae, although no species reported there show close similarity. The São Tomé taxon has unusual mucronate pleurocystidia similar to those of $P$. maculata (C.S. Parker) A.H. Sm. and $P$. mucrocystis A.H. Sm., but those species differ in nearly all other taxonomically significant features (Smith 1972). Interestingly, an ITS sequence of the São Tomé specimen matches with 99.1\% similarity a sequence determined as $P$. maculata from Korea (KR673679). Except for the mucronate cystidia, nothing in the morphology of the São Tomé specimen suggests it is conspecific with $P$. maculata, and we recognize the identification of the material associated with the GenBank sequence as erroneous. For example, $P$. maculata, a species described from decaying Alnus logs on Mt. Rainier, Washington (USA), forms robust basidiomes with an appressed-fibrillose, maculate pileus 20-60 mm broad, a densely fibrillose stipe 60-120 × 6-14 mm, a well-developed, submembranous partial veil that remains as patches along the pileus margin or as an apical annulus, and distinctive caulocystidia. In comparison, $P$. oboensis has a small $(7-18 \mathrm{~mm})$, glabrous pileus, a glabrous, much smaller stipe (20-48 $\times 1-2 \mathrm{~mm})$, lacks a partial veil and caulocystidia, and grows in a tropical forest. Compare the photos of Smith (1972, Pls. 13 \& 14) with the one presented here.

The European $P$. laevissima (Romagn.) Singer has similar small basidiospores and mucronate pleurocystidia, but it forms larger $(10-45 \mathrm{~mm})$, convex, striate pilei, broader lamellae $(2-3 \mathrm{~mm})$, larger pleurocystidia $(20-45 \times 10-17.5 \mu \mathrm{m})$ that are faintly pigmented, some mucronate cheilocystidia, and grows on wood in temperate deciduous forests (Kits Van Waveren 1985, Orstadius and Knudsen 2008). Psathyrella chiloensis Singer is apparently also similar but poorly known - described from a single collection among mosses on a dead tree in Chile. The protologue is similar to the São Tomé specimen, differing in forming larger pilei ( $-28 \mathrm{~mm}$ diam), having a poorly developed partial veil, and broader pleurocystidia (11-14 $\mu \mathrm{m})$ (Singer 1969).

\section{Strophariaceae}

Deconica overeemii (E. Horak \& Desjardin) Desjardin \& B.A. Perry, comb. nov. Figs. 21, 22a-e Basionym: Psilocybe overeemii E. Horak \& Desjardin, Sydowia 58: 30. 2006. Mycobank MB 816224

Pileus 8-12 mm diam, broadly convex to plano-convex with a prominent, acute conical papilla, non-striate; surface dull, dry, appressed-fibrillose-tufted, with a few scattered veil fibrils, at first grayish brown (6D3) with a paler papilla, in age cream (4A3) overall. Context $<1 \mathrm{~mm}$ thick, soft, white, not staining. Lamellae horizontal, adnate, close with 2 series of lamellulae, broad $(-1.5$ $\mathrm{mm}$ ), brown (7E6-8) to dark brown (7F6-7). Stipe 15-22 × 1-1.5 mm, central, terete, cylindrical above a subbulbous base, hollow; surface dull, dry, appressed-fibrillose, grayish brown (6D3). 
Partial veil evanescent, membranous, remaining as a few white fibrillose patches on pileus margin, absent on stipe surface. Odor and taste not recorded.

Basidiospores 5.2-6 $\times$ 4.5-5.5. $\mu \mathrm{m}$ (face view) $\times 3.7-5 \mu \mathrm{m}$ (profile), rhomboid to mitriform in face view, amygdaliform in profile, with a prominent germ pore, smooth, distinctly thick-walled $(0.5-1 \mu \mathrm{m})$, brown. Basidia 18-20 × 5.5-6.5 $\mu \mathrm{m}$, clavate, 4-spored. Basidioles clavate. Pleurocystidia 19-26 $\times 8.5-13 \mu \mathrm{m}$, broadly clavate to clavate-mucronate, thin-walled or slightly thick-walled at apex, hyaline with refractive, golden contents in Melzer's reagent (chrysocystidialike). Cheilocystidia common, lamellar edge fertile, 17-23 × 4.5-6.5 $\mu \mathrm{m}$, subfusoid to lageniform, hyaline, thin-walled. Pileipellis a cutis of cylindrical, smooth or roughened-incrusted hyphae 4-6.5 $\mu \mathrm{m}$ diam, non-inflated, hyaline to yellowish brown, inamyloid, non-gelatinous. Pileus trama and lamellar trama hyphae similar. Stipitipellis of somewhat interwoven hyphae $2.5-5 \mu \mathrm{m}$ diam, branched, hyaline, smooth or pale yellowish brown-incrusted, giving rise to caulocystidia 25-35 $\times$ 3.5-6 $\mu \mathrm{m}$, irregularly cylindrical, seldom with a knob-like outgrowth. Clamp connections present.

Habitat and known distribution - Solitary on rotten wood in primary forest. Africa (São Tomé), Indonesia (Java).

Material examined - Africa, São Tomé island, Macambrara radio antenna area, N0 ${ }^{\circ} 16.557^{\prime}$, E6 36.326', elev. 1300m, 25 April 2008, coll. by D.E. Desjardin, DED8328 (SFSU; KX017212).

Notes - Deconica overeemii is distinct because of the small basidiomes with a pileus that has a prominent, acute conical papilla, small rhomboid-mitriform basidiospores, clavate-mucronate chrysocystidia-like pleurocystidia, subfusoid-lageniform cheilocystidia, and an evanescent partial veil that may leave remnants on the pileus margin. Described originally from Java (Horak \& Desjardin 2006), the São Tomé material differs only slightly from the protologue in forming a longer stipe and slightly larger basidiospores (4.5-5.5 $\times 4-5 \times 3-3.5 \mu \mathrm{m}$ in Java). An ITS sequence of DED8328 shows 92.7-96.7\% similarity to several GenBank sequences (KC669313, KC669314, KC669315, KM270756) of undetermined Deconica species.

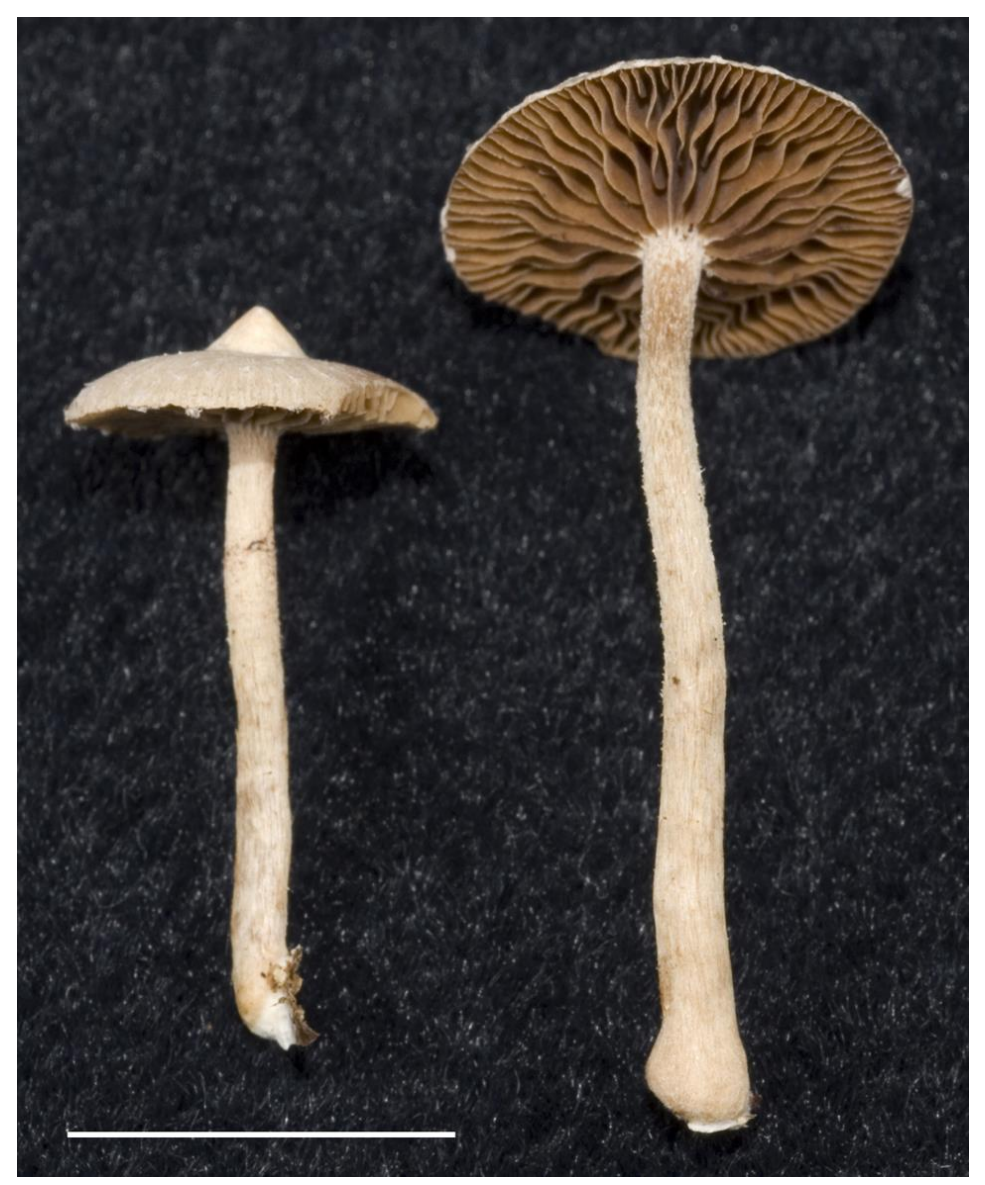

Fig. 21 - Basidiomes of Deconica overeemii (DED8328). Scale bar $=10 \mathrm{~mm}$. 

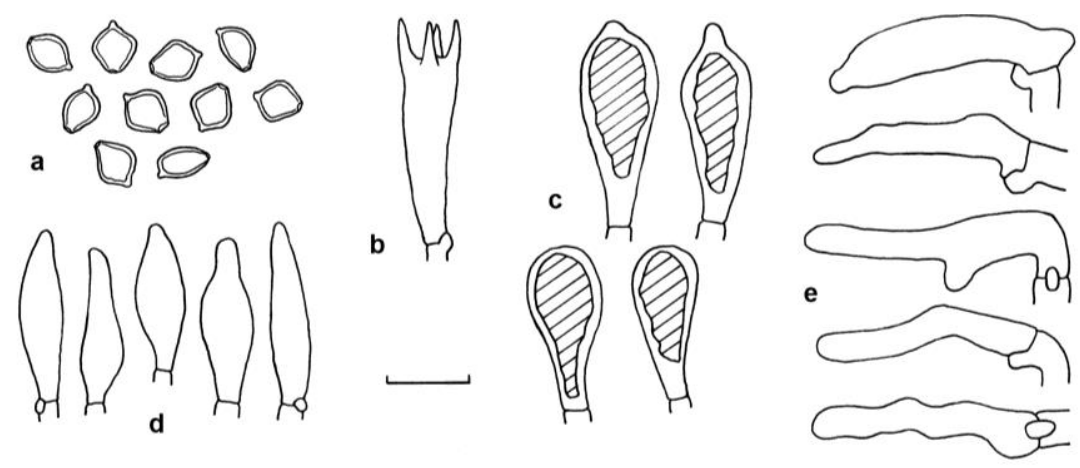

Fig. 22 - Micromorphological features of Deconica overeemii (DED8328). a. Basidiospores. b. Basidium. c. Pleurocystidia. d. Cheilocystidia. e. Caulocystidia. Scale bar $=10 \mu \mathrm{m}$.

Deconica protea (Kalchbr.) Desjardin \& B.A. Perry, comb. nov.

Figs. 23, 24a-c

Basionym: Agaricus proteus Kalchbr. apud Thüm., Mycoth. Univ., Cent. 6: no. 503. 1876.

= Cladopus proteus (Kalchbr.) Kalchbr., ibid.

= Melanotus proteus (Kalchbr.) Singer, Lloydia 9: 130. 1946.

= Crepidotus proteus (Kalchbr.) Pilát, Trans. Brit. Mycol. Soc. 33: 231. 1950.

Mycobank MB 816225

Pileus 5-13 mm diam, broadly plano-convex in front view, orbicular to chordate in top view, margin even or short striatulate; surface dull, moist to dry, glabrous to appressed-felted, hygrophanous, disc yellowish-golden, margin pale ash gray, fading to white with moisture loss. Context $<1 \mathrm{~mm}$ thick, white. Lamellae adnexed to shallowly adnate, close to crowded with 2 series of lamellulae, moderately broad $(-1 \mathrm{~mm})$, initially gray, becoming mottled gray to purplish brown (9F4-5). Stipe 1-2 $\times 0.5-1 \mathrm{~mm}$, strongly eccentric to nearly lateral, terete, cylindrical above a broadened base, curved; surface glabrous to appressed fibrillose, base with scant white tomentum, dingy white to dull brown. Odor indistinct.

Basidiospores 5.5-6.7 $\times 4-5 \mu \mathrm{m}$ (face view) $\times 3.8-4.5 \mu \mathrm{m}$ (profile), ellipsoid in face view, lenticular to amygdaliform in profile, with a broad germ pore, smooth, distinctly thick-walled (0.5$1 \mu \mathrm{m})$, dark gray to dark grayish brown. Basidia 16-20 $\times 5-6 \mu \mathrm{m}$, urniform, 4-spored. Basidioles clavate. Pleurocystidia absent. Cheilocystidia common, lamellar edge mostly sterile, 21-30 (-48) $\times$ 4-6 $\mu \mathrm{m}$, fusoid-ventricose to lageniform with an elongated neck 11-34 $\times 2-3 \mu \mathrm{m}$, hyaline, thinwalled. Pileipellis a cutis of repent, interwoven, cylindrical to sinuous hyphae $3.2-7 \mu \mathrm{m}$ diam, hyaline or seldom very pale yellowish brown, thick-walled, non-incrusted, non-gelatinous. Pileus trama and lamellar trama hyphae similar. Clamp connections present.

Habitat and known distribution - Scattered to gregarious on twigs and woody debris. Africa (Kenya, São Tomé, South Africa, Tanzania), possibly Sri Lanka.

Material examined - Africa, São Tomé island, Macambrara radio antenna area, N0 ${ }^{\circ} 16.557^{\prime}$, E6 36.326', elev. 1300m, 11 April 2008, coll. by B.A. Perry, BAP596 (SFSU; KX017213); São Tomé island, Parque Nacional Obo, trail to Lagoa Amelia, between N0 ${ }^{\circ} 17.112^{\prime}$, E6 $35.967^{\prime}$ and N0 ${ }^{\circ} 16.922^{\prime}, \mathrm{E}^{\circ} 36.062 ', 14$ April 2008, coll. by D.E. Desjardin, DED8245 (SFSU).

Notes - Deconica protea is characterized by small, pallid basidiomes with a tiny, strongly eccentric stipe, thick-walled, lenticular basidiospores 5.5-6.7 $\times 4-5 \mu \mathrm{m}$, fusoid to lageniform cheilocystidia with elongated neck, a cutis-type pileipellis of mostly hyaline, non-incrusted hyphae, and growth on woody debris in tropical forests. Although Species Fungorum recognizes Melanotus proteus as a synonym of Deconica horizontalis (Bull.) Noordel., we accept it as a distinct species, following Horak (1977), Pegler (1977), Redhead and Kroeger (1984), and Watling and Gregory (1987). The São Tomé specimens match the African material reported by Pegler (1977) in gray pileus becoming white with moisture loss, strongly eccentric to almost lateral stipe, distinctly thickwalled, lenticular basidiospores, and cheilocystidia with elongated neck. Deconica horizontalis forms larger pilei ( $-30 \mathrm{~mm}$ diam) pigmented rusty brown, brown or reddish brown becoming cinnamon brown with moisture loss, a longer, less eccentric stipe, thinner walled, more ellipsoid basidiospores and cheilocystidia with less elongated neck. 


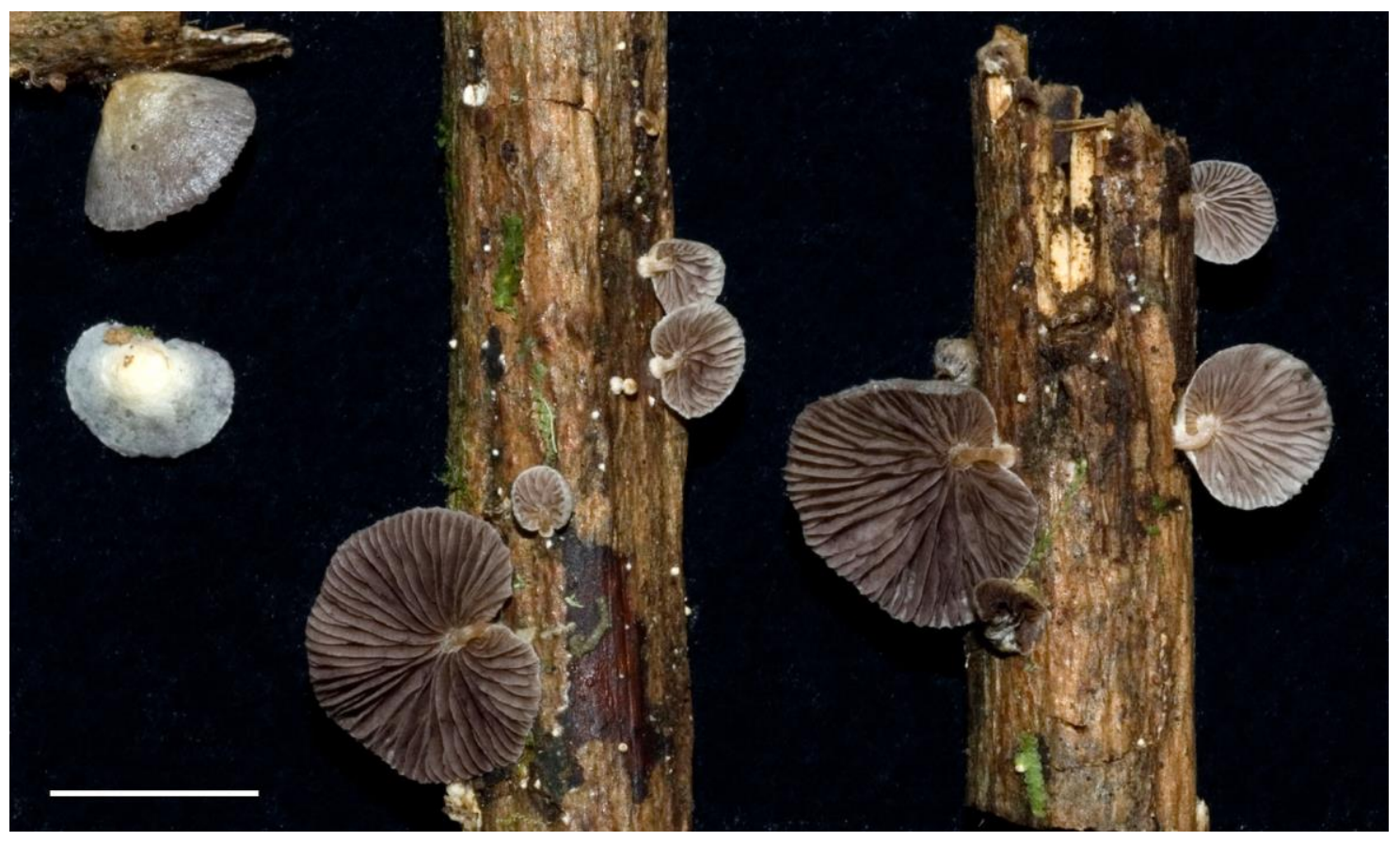

Fig. 23 - Basidiomes of Deconica protea (BAP596). Scale bar $=10 \mathrm{~mm}$.
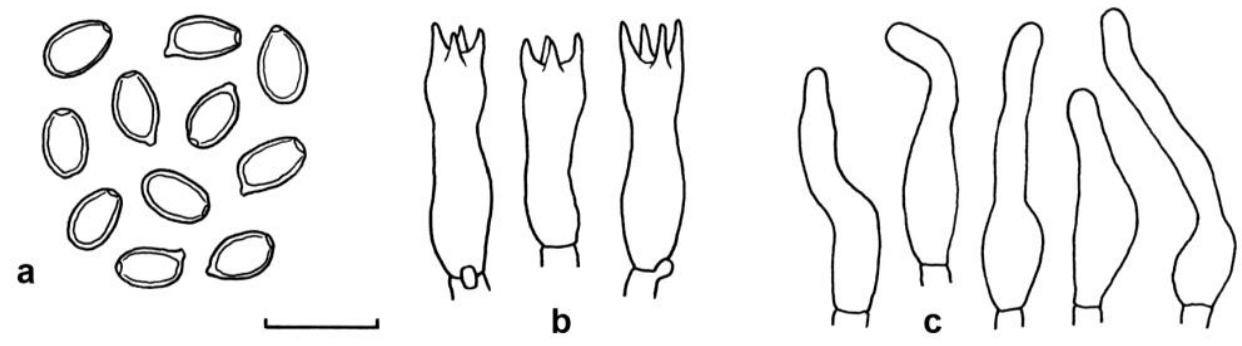

Fig. 24 - Micromorphological features of Deconica protea (BAP596). a. Basidiospores. b. Basidia. c. Cheilocystidia. Scale bar $=10 \mu \mathrm{m}$.

An ITS sequence of BAP596 shows $98.6 \%$ similarity to a GenBank sequence determined as Deconica citrispora (KM975431) from New Zealand, but the latter species differs significantly in morphology in forming smaller basidiomes (pileus $-6 \mathrm{~mm}$ diam) with thin-walled, limoniform basidiospores 10-13 $\times 9-12 \mu \mathrm{m}$, basidia 25-35 $\times 12-15 \mu \mathrm{m}$, and growth on dead monocotyledonous leaves (Horak 1977).

Hypholoma aff. subviride (Berk. \& M.A. Curtis) Dennis, Kew Bull. 15(1): 134. 1961.

Figs. 25, 26a-d, 27

Pileus 8-20 mm diam, obtusely conical to campanulate, expanding to broadly convex with a distinct obtusely conical umbo, seldom without umbo; margin even or cleft, incurved to decurved, pellucid-striate; surface moist to dry, covered by a thin layer of scattered white to pale yellowish white fibrils, disc pale grayish yellow (4B3-4) to grayish orange (5B4) or paler, margin yellowish white (3A2), sometimes with a hint of green (3B2). Context 1-2 mm thick, watery-concolorous with surface. Odor indistinct; taste very bitter. Lamellae shallowly adnexed to adnate with a decurrent tooth, crowded with 3 series of lamellulae, narrow $(1-1.5 \mathrm{~mm})$, white to pale yellowish white when young, soon grayish olive-yellow (4C5-6), in age with dark grayish brown tones (5F3). Stipe 10-35 $\times 1-2 \mathrm{~mm}$, central, terete, cylindrical or very slightly enlarged downward, fistulose; surface dull, dry, furfuraceous to fibrillose, when young pale yellowish white to pale yellow (3A23 ) or cream (4A3, base darkening in age to grayish orange (5B4) or sometimes brownish orange (6C4), very base with white strigose hairs; partial veil not evident on youngest fresh basidiomes. 
Basidiospores 6.5-7.5 × 3.8-4.5 $\mu \mathrm{m}\left[\mathrm{x}_{\mathrm{m}}=6.8 \pm 0.3 \times 4.2 \pm 0.2 \mu \mathrm{m}, \mathrm{Q}=1.5-1.8, \mathrm{Q}_{\mathrm{m}}=1.6\right.$ $\pm 0.1, \mathrm{n}=25, \mathrm{~s}=1$ ], ellipsoid to amygdaliform, truncate, smooth, with a broad germ pore, brown. Basidia 16-18 × 6.4-7.0 $\mu \mathrm{m}$, clavate, 4-spored. Basidioles clavate. Cheilocystidia abundant, lamellar edge sterile, 17-26 × 6.5-8.0 $\mu \mathrm{m}$, subcylindrical to subfusoid or ventricose, obtuse, hyaline, thin-walled. Chrysocystidia abundant as pleurocystidia and scattered on lamellar edge, 22$26 \times 6.5-9.5 \mu \mathrm{m}$, broadly clavate, often mucronate, hyaline with yellow to golden, resinousamorphous contents, thin-walled. Pileipellis a cutis of repent, cylindrical hyphae 4-8 $\mu \mathrm{m}$ diam, incrusted, hyaline to golden, non-gelatinous, thin-walled, forming a thin layer up to $35 \mu \mathrm{m}$ thick overlaying a hypodermium of ellipsoid to vesiculose cells $16-48 \times 12-20 \mu \mathrm{m}$, non-incrusted, hyaline, non-gelatinous, thin-walled. Pileus trama of tightly interwoven hyphae $4-10 \mu \mathrm{m}$ diam, cylindrical or irregular in outline, hyaline, non-gelatinous, thin-walled. Stipitipellis a cutis of parallel cortical hyphae 2.5-6.5 $\mu \mathrm{m}$ diam, cylindrical, incrusted, hyaline to yellow, non-gelatinous, thin-walled, a few loosely arranged; medullary hyphae 3.5-12 $\mu \mathrm{m}$ diam, cylindrical to inflated, hyaline, non-gelatinous, thin-walled, with scattered oleiferous hyphae with golden resinous contents. Caulocystidia absent. Clamp connections present.

Habitat and known distribution - In small cespitose clusters, in troops of hundreds on rotten logs of undetermined dicotyledonous trees in primary forests. Africa (São Tomé).

Material examined - Africa, São Tomé island, Parque Nacional Obo, trail to Lagoa Amelia, between $\mathrm{N} 0^{\circ} 17.112^{\prime}, \mathrm{E}^{\circ} 35.967^{\prime}$ and $\mathrm{N} 0^{\circ} 16.922^{\prime}, \mathrm{E}^{\circ}{ }^{\circ} 36.062^{\prime}, 14$ April 2008, coll. by D.E. Desjardin, DED8236 (SFSU; [15-29] KX017214); São Tomé island, Macambrara radio antenna area, N0¹6.557', E6 36.326', elev. 1300m, 11 April 2008, coll. by Rebecca Wenk, BAP590 (SFSU; [15-30] KX017215); same location, 25 April 2006, coll. by D.E. Desjardin (material lost).

Notes - The São Tomé material forms small cespitose basidiomes densely gregarious on rotten wood in primary forests, with small $(8-20 \mathrm{~mm}$ diam), obtusely conical-umbonate, pale yellowish white pilei with grayish orange disc, narrow, crowded lamellae, and small (10-35 $\times 1-2$ $\mathrm{mm}$ ), yellowish white stipes with grayish orange bases. It is distinct micromorphologically by relatively small (mean $6.8 \times 4.2 \mu \mathrm{m}$ ), truncate, brown basidiospores with a broad germ pore, ventricose-obtuse cheilocystidia, broadly clavate-mucronate chrysocystidia, and a thin cutis-type pileipellis overlaying a hypodermium.

The São Tomé material matches what Pegler (1977) reported from East Africa as $H$. subviride, a species described originally from Cuba. Some authors (and Species Fungorum) accept $H$. subviride as a synonym of $H$. fasciculare (Huds.) P. Kumm., while others recognize the latter as two distinct species. We generated an ITS-based phylogeny from all available sequences of a broad sampling of Hypholoma species (Fig. 27), and it clearly delimits a well-supported fasciculare/subviride clade (99\% BS, 1.0 PP) sister to H. brunneum (Massee) D.A. Reid. The clade consists of four relatively well-supported internal clades that represent geographically distant taxa. One clade, basal to the other three, consists of the two specimens reported here from São Tomé plus a specimen from Puerto Rico deposited as Hypholoma cf. subviride. The latter could represent a slave trade-mediated introduction from São Tomé into Puerto Rico. A second internal clade consists of north temperate, primarily European and Chinese specimens of $H$. fasciculare. A third clade represents $H$. acutum from Australia and New Zealand, while the fourth clade represents $H$. subviride. The subviride clade is subdivided into a clade from the southeastern USA plus Caribbean region (type locality), and a clade from Japan plus South Korea. These genetically distinct lineages may represent different species, or if interfertile, different varieties of $H$. fasciculare. Several Old World putative synonyms of $H$. subviride have been reported, including $H$. janus (Berk. \& Broome) Petch from Sri Lanka, Pholiota aggregata Beeli from DR Congo, and several unpublished type studies (E. Horak, pers. comm.). Whether these taxa or others represent an available name for the São Tomé taxon is unknown without further studies and fresh material for sequence comparisons. Until then, based primarily on phenetic similarity, we refer to our material as $H$. aff. subviride. 


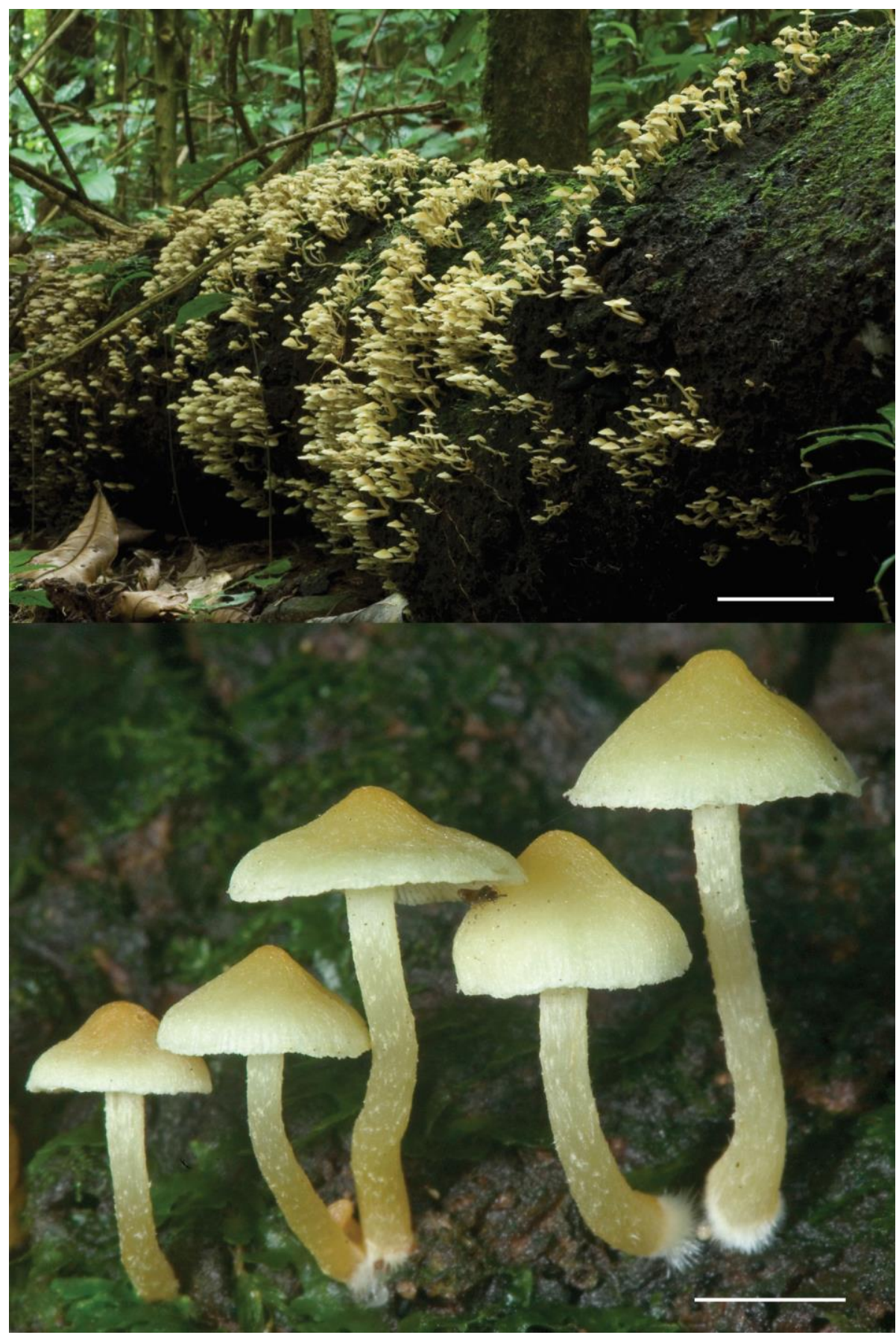

Fig. 25 (above) - Basidiomes of $H$. aff. subviride (DED8236). Scale bar = $100 \mathrm{~mm}$ (top), $10 \mathrm{~mm}$ (bottom).

\section{Poorly Known Species Reported from São Tomé and Príncipe}

Agaricus macromastes Fr., Nova Acta R. Soc. Scient. Upsal., Ser. 3, 1: 226. 1851. = Galera macromastes (Fr.) Sacc., Syll. Fung. (Abellini) 5: 866. 1887.

This is apparently known only from the protologue of Fries (1851), copied by Saccardo and transferred to Galera. Fries described a species with pallid, glabrous, cylindrical to conicalumbonate pileus about $10-40 \mathrm{~mm}$ diam with a straight margin appressed to the stipe, free, narrow lamellae with ochraceous-ferruginous spores, and a hollow, glabrous, pallid, initially conical stipe 35-40 $\mathrm{mm}$ long with an apex $5 \mathrm{~mm}$ diam and base 6-12 $\mathrm{mm}$ diam. This could represent a robust species of Conocybe, one that we have not encountered on São Tomé. Index Fungorum reports the taxon only as Galera macromastes Fr. 


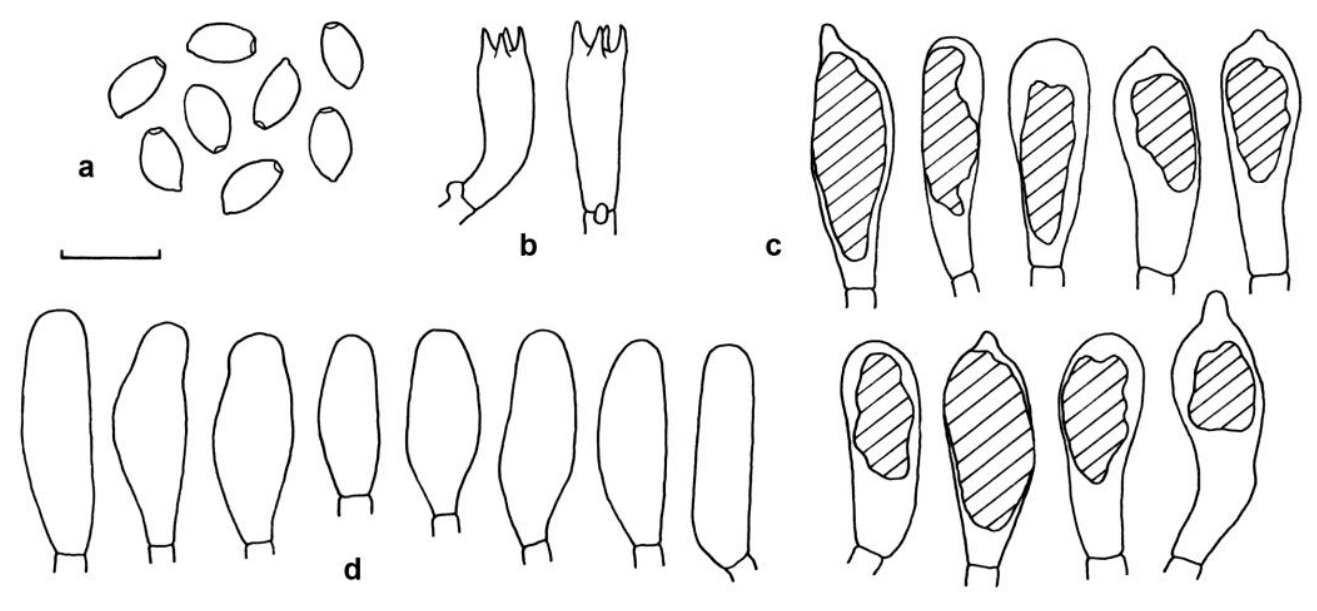

Fig. 26 - Micromorphological features of $H$. aff. subviride (DED8236). a. Basidiospores. b. Basidia. c. Chrysocystidia. d. Cheilocystidia. Scale bar $=10 \mu \mathrm{m}$.

Agaricus papularis Fr., Nova Acta R. Soc. Scient. Upsal., Ser. 3, 1: 225.1851. = Naucoria papularis (Fr.) Sacc., Syll. Fung. (Abellini) 5: 856. 1887.

The original description of Fries (1851) and redescription by Coutinho (1925) indicate a species with a plano-convex-depressed, papillose, nearly white pileus, adnate-decurrent, close, broad, cinnamon-ferruginous lamellae, a pallid, fibrillose-striate stipe 50-80 × 3-10 mm that grows on dry wood, and yellow ("sub vitro lutescentes") basidiospores 6-8 $\times 5-6 \mu \mathrm{m}$. Coutinho (1925) compared the new species to P. muricella (Fr.) Bon. We have not encountered a taxon that matches the published descriptions. Index Fungorum reports the taxon only as Agaricus papularis Fr.

Inocybe hystrix (Fr.) P. Karst., Bidr. Känn. Finl. Nat. Folk 32: 453. 1879. = Agaricus hystrix Fr., Epicr. Syst. Mycol. (Upsaliae): 171. 1838. (1836-1838).

Coutinho (1925) reports the São Tomé material as a rather large species with a brown, squamose-squarrose, subumbonate pileus 50-70 mm diam, adnexed, close, rusty brown lamellae, a brown, squamose-squarrose stipe $70-90 \times 14 \mathrm{~mm}$ that grows on dry wood, and tawny ("sub vitro fulventes") basidiospores 9-19 × 6-7 $\mu \mathrm{m}$. We have not encountered any taxa that match this description, and the lignicolous habit and spore color suggest Coutinho's taxon does not represent $I$. hystrix.

Inocybe reticulata Cout., Anais Inst. Sup. Agron. Univ. Téc. Lisboa 2: 20. 1925.

Coutinho (1925) described the new species as forming a plano-subumbonate, radially fibrillose-reticulate pileus $60-90 \mathrm{~mm}$ diam that is pale brownish yellow with a brown disc, adnexed, close, broadly ventricose, yellowish cinnamon lamellae, a glabrous, cylindrical, yellowferruginous stipe 50-70 $\times 5-10 \mathrm{~mm}$ that grows on dry wood, and yellow ("sub vitro luteae") basidiospores 6-7 × 5-6 $\mu \mathrm{m}$. He compared I. reticulata to I. perlata (Cooke) Sacc. We have not encountered any Inocybe species on São Tomé, nor do they normally grow on dry wood. Species Fungorum lists the current name as Inocybe reticulata.

Naucoria brevipes Cout., Anais Inst. Sup. Agron. Univ. Téc. Lisboa 2: 21.1925.

Coutinho (1925) described the species as forming a yellowish brown, striate, plano-convex pileus $30-80 \mathrm{~mm}$ diam covered centrally with obscure squamules, adnate-subdecurrent, close, broad, ferruginous-cinnamon lamellae, a fleshy-fibrous stipe 20-50 $\times 5-8 \mathrm{~mm}$ that grows on dead wood, and ferruginous, subglobose to ellipsoid basidiospores 6-7 $\times 5-6 \mu \mathrm{m}$ diam. Although Coutinho (1925) suggested that the species may belong in Flammula, it was never formally transferred there. We have not encountered this taxon on São Tomé. Species Fungorum lists the current name as Naucoria brevipes. 


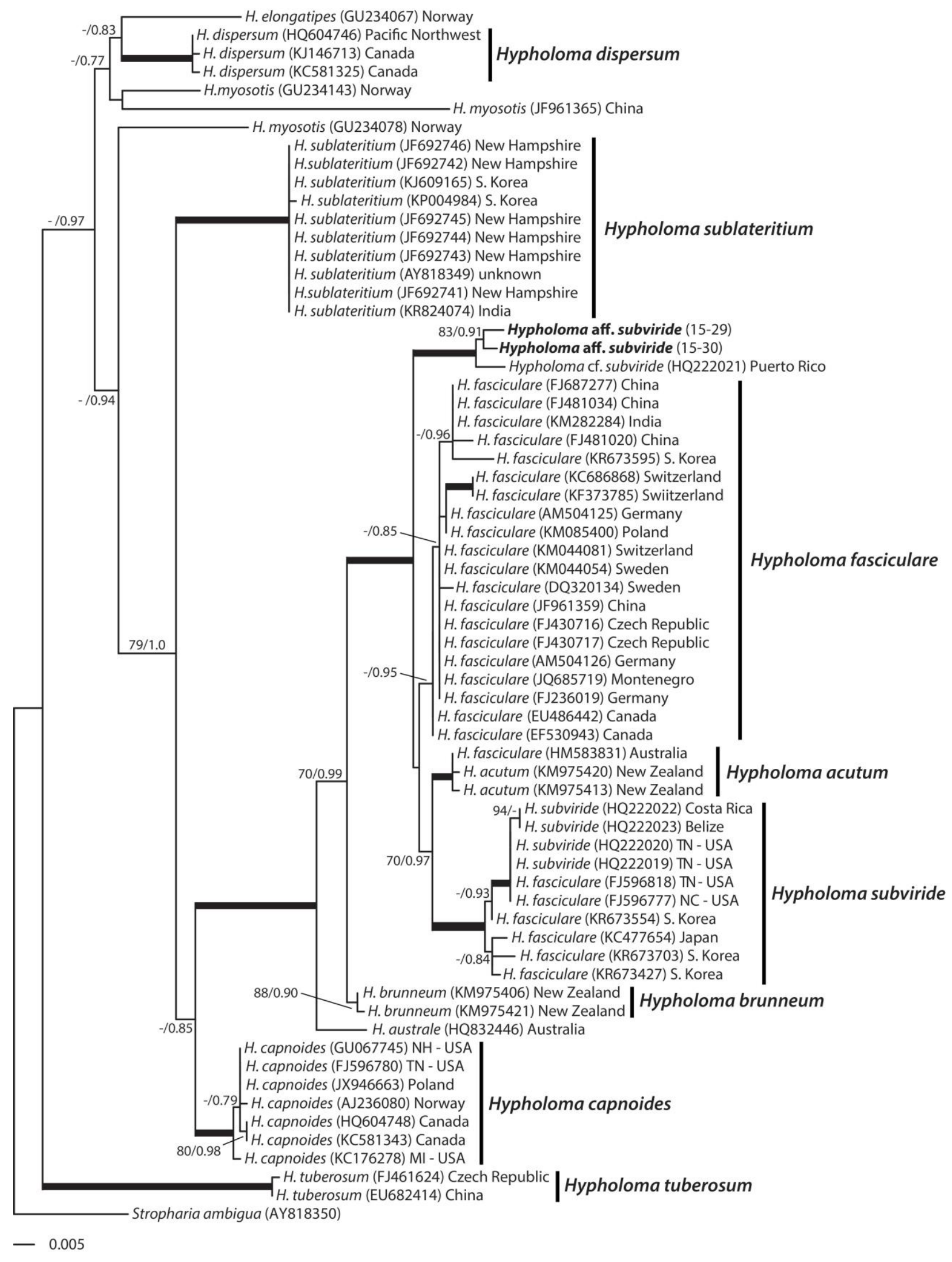

Fig. 27 (above) - Maximum likelihood phylogeny of Hypholoma based on ITS sequence data ( $\ln L$ $=-2667.5966$ ). Sequences of the African material (Hypholoma aff. subviride) are indicated in bold type. Values separated by / refer to nonparametric ML bootstrap proportions and Bayesian posterior probabilities. Only values greater than $70 / 0.70$ are shown (- designates a value below $70 \%$ or 0.70 ). Nodes receiving support values greater than 90/0.95 are highlighted in bold. 
Naucoria chrysotricha (Berk. \& M.A. Curtis) Cout., Anais Inst. Sup. Agron. Univ. Téc. Lisboa 2: 21. 1925.

= Agaricus chrysotricha Berk. \& M.A. Curtis, J. Linn. Soc., Bot. 10(45): 290. 1868 (1869).

= Flammula chrysotricha (Berk. \& M.A. Curtis) Pat., in Duss, Enum. Champ. Guadeloupe (Lonsle-Saunier): 54. 1903.

Coutinho (1925) reported the São Tomé material as having an appressed-fibrillose, golden brown, plano-convex pileus $25-50 \mathrm{~mm}$ diam, adnexed, close, broad, cinnamon-ferruginous lamellae, a fibrillose, curved, black-brown (when dried) stipe 15-20 $\times 3-5 \mathrm{~mm}$ that grows on dead wood, and ferruginous basidiospores $6-7 \times 3.5-4 \mu \mathrm{m}$. We have not encountered a taxon that matches this description. Species Fungorum lists the current name as Naucoria chrysotricha.

Naucoria fusco-olivacea Bres. \& Roum., Revue Mycol., Toulouse 12: 28. 1890.

Bresadola and Roumeguere (1890) described the species from São Tomé as having a conical-campanulate to plane-depressed, pruinose, striate, reticulate-venose, fusco-olivaceous pileus $20 \mathrm{~mm}$ diam, subdistant, adnate, concolorous lamellae with pruinose edges, a glabrescent, olive-velutinous, smoky red (rufofuscus) stipe 60-70 $\times 2 \mathrm{~mm}$, yellowish gold basidiospores 8-10 $\times$ 5-6 $\mu \mathrm{m}$, and growth on logs. They compared it with Simocybe centunculus (Fr.) P. Karst. (as Naucoria centunculus), which differs in forming smaller basidiomes with smaller basidiospores. The taxon may very well represent a species of Simocybe that we have not encountered on São Tomé, but compare with Simocybe centunculus described above. Index Fungorum reports the species as Naucoria fusco-olivacea Bres. \& Roum.

Pholiota aculeata Bres. \& Roum., Revue Mycol., Toulouse 12: 28. 1890.

= Gymnopilus aculeatus (Bres. \& Roum.) Singer, Lilloa 22: 561. 1951. (1949).

Described from São Tomé, Bresadola and Roumeguere (1890) reported a species with yellow, squamose-aculeate pileus 10-15 mm diam, adnate, close, yellow-tawny lamellae, and a stuffed, furfuraceous stipe 15-20 × 1-2 mm with yellow apex, ferruginous base, and an inferior, lacerate, evanescent annulus. The spores were reported as 6-7 $\times 4-4.5 \mu \mathrm{m}$, subamygdaliform, yellow-tawny. Singer included the species in Gymnopilus sect. Annulati, although it is uncertain if he studied the type. The original authors compared $P$. aculeata to a small P. lucifera (Lasch) Quél. We have not encountered a taxon that matches the protologue.

\section{Acknowledgments}

Foremost we thank Dr. Robert C. Drewes who continues to initiate, coordinate and lead multiorganism biotic surveys on São Tomé and Príncipe. We thank Eng. Arlindo de Ceita Carvalho, Director General of the Ministry of Environment, Victor Bonfim, Salvador Sousa Pontes and Danilo Barbero for permission to collect and export specimens for study. We are indebted to Société de Conservation et Développement for logistics and housing support, especially the wonderful staffs of Omali Lodge and Bom Bom Island. We are grateful for the support and cooperation of Bastien Loloumb of Zuntabawe and Faustino Oliviera, former Director of the botanical garden at Bom Sucesso. We were assisted in the field by Jose Ramos Maria Vital Pires on Príncipe and by Quintino Quade Cabral, Martinho Nascimiento and Jose Clara on São Tomé. For continuing support, we are most grateful to Ned Seligman, Quintino Quade Cabral and Roberta dos Santos of STePUP. We are grateful to the College of Science and Engineering at San Francisco State University for partial funding to support travel to São Tomé and Príncipe, and to the G. Lindsay Field Research Fund of the California Academy of Sciences (CAS) for financially supporting the expedition in 2006 and the Hagey Research Venture Fund (CAS) in 2008. Lastly, we are most thankful to several anonymous gentlemen who provided funding to support all aspects of this research.

\section{References}

Berkeley MJ, Broome CE. 1871 - The fungi of Ceylon (Hymenomycetes, from Agaricus to 
Cantharellus). Journal of the Linnean Society, Botany 11, 494-567.

Bresadola G, Roumeguère, C. 1890 - Nouvelles contributions à la Flore mycologique des Iles Saint-Thomé et des Princes, recuilles par MM. Ad, F. Moller, F. Quintas, et F. Newton. Revue Mycologique, Toulouse 12(45), 25-40.

Coutinho AXP. 1925 - Florae mycologicae insulae St. Thomae. Anais do Instituto superior de Agronomia Universidade Técnica de Lisboa 2, 1-26.

Darriba D, Taboada GL, Doallo R, Posada D. 2012 - jModelTest 2: more models, new heuristics and parallel computing. Nature Methods 9(8), 772.

Desjardin DE, Perry BA. 2009 - A new species of Phallus from São Tomé, Africa. Mycologia 101(4), 543-545.

Desjardin DE, Perry BA. 2015a - A new species of Scytinopogon from the island of Príncipe, Republic of São Tomé and Príncipe, West Africa. Mycosphere 6(4), 434-441.

Desjardin DE, Perry BA. 2015b - Clavarioid fungi and Gasteromycetes from the Republic of São Tomé and Príncipa, West Africa. Mycosphere 6(4), 515-531.

Fries E. 1851 - Novarum symbolarum mycologicarum Mantissa. Nova Acta R. Soc. Scient. Upsal., Ser. 3, 1, 225-231.

Gardes M, Bruns TD. 1993 - ITS primers with enhanced specificity for basidiomycetes application to the identification of mycorrhizae and rusts. Molecular Ecology 2, 113-118.

Guindon S and Gascuel O. 2003 - A simple, fast and accurate method to estimate large phylogenies by maximum-likelihood". Systematic Biology 52, 696-704.

Guzmán-Dávalos LG, Contu M, Ortega A, Vizini A, Herrera M, Ovrebo C, Rodríguez A, Villalobos-Arámbula AR, Palomera V, Vargas G, Santerre A. 2008 - New morphological and molecular data on Gymnopilus purpureosquamulosus and its phylogenetic relationships among similar species. Sydowia 60(1), 41-56.

Guzmán-Dávalos LG, Mueller GM, Cifuentes J, Miller AN, Santerre A. 2003 - Traditional infrageneric classification of Gymnopilus is not supported by ribosomal DNA sequence data. Mycologia 95(6), 1204-1214.

Hesler LR, Smith AH. 1965 - North American species of Crepidotus. Hafner Publishing Co., New York and London.

Høiland K. 1998 - Gymnopilus purpureosquamulosus and G. ochraceus spp. nov. (Agaricales, Basidiomycota) - two new species from Zimbabwe. Mycotaxon 69, 81-85.

Horak E, Desjardin DE, Hemmes DE. 1996 - Agaricales of the Hawaiia Islands. 3: The genus Galerina and selected other brown-spored agarics. Mycologia 88(2), 278-294.

Horak E, Hausknecht A. 2002 - Notes on extra-European taxa of Bolbitiaceae (Agaricales, Basidiomycota). Österreichische Zeitschrift für Pilzkunde 11: 213-264.

Horak E. 1977 - The genus Melanotus Pat. Persoonia 9(3), 305-327.

Huelsenbeck JP, Ronquist F. 2001 - MrBayes: Bayesian inference of phylogeny. Bioinformatics 17, 754-755.

Kasuya T, Uno K, Hosaka K. 2014 - Reexamination of Crepidotus crocophyllus (Basidiomycota, fungi) in Japan, with reference to its phylogenetic placement. University Bulletin of the Chiba Institute of Science 7, 159-166.

Kits Van Waveren E. 1985 - The Dutch, French and British species of Psathyrella. Persoonia Supplement Vol. 2, 1-300.

Kornerup A, Wanscher JH. 1978 - Methuen Handbook of Colour. 3rd ed. Eyre Methuen, London.

Larkin MA, Blackshields G, Brown NP, Chenna R, McGettigan PA, McWilliam H, Valentin F, Wallace IM, Wilm A, Lopez R, Thompson JD, Gibson TJ, Higgins DG. 2007 - Clustal W and Clustal X version 2.0. Bioinformatics 23, 2947-2948.

Maddison WP, Maddison, DR. 2015 - Mesquite: a modular system for evolutionary analysis. Version 3.04 (http://mesquiteproject.org).

Murrill WA. 1918 - The Agaricaceae of tropical North America-VII. Mycologia 10: 15-33.

Örstadius L, Knudsen H. 2008 - Psathyrella (Fr.) Quél. In: Funga Nordica. Knudsen H, Vesterholt J. Eds. Nordsvamp, Copenhagen. pp 586-623. 
Pegler DN. 1977 - A preliminary agaric flora of East Africa. Kew Bulletin Additional Series 6, 1615.

Pegler DN. 1986 - Agaric flora of Sri Lanka. Kew Bulletin Additional Series 12, 1-519.

Perry BA, Hansen K, Pfister DH. 2007 - A phylogenetic overview of the family Pyronemataceae (Ascomycota, Pezizales). Mycological Research 111, 549-571.

Pure Culture. Persoonia 16(4): 549-551.

Redhead SA, Kroeger P. 1984 - Melanotus textilis, a new fabric- and wood-inhabiting North American agaric. Mycologia 76(5), 868-872.

Reid DA. 1984 - A revision of the British species of Naucoria sensu lato. Transactions of the British Mycological Society 82(2), 191-237.

Ronquist F, Huelsenbeck JP. 2003 - MrBayes 3: Bayesian phylogenetic inference under mixed models. Bioinformatics 19, 1572-1574.

Saccardo PA, Berlese AN. 1889 - Mycetes aliquot Guineenses a clar. Moller et F. Newton lecti in ins. S. Thomae et Principis. Boletim da Sociedade Broteriana 7, 110-114.

Singer R, Digilio APL. 1952. Pródromo de la Flora Agaricina Argentina. Lilloa 25, 1-461.

Singer R. 1969 - Mycoflora Australis. Beihefte zur Nova Hedwigia 29, 1-405.

Smith AH. 1972 - The North American species of Psathyrella. Memoirs of the New York Botanical Garden 24, 1-633.

Stamatakis, A. 2014 - RAxML Version 8: A tool for Phylogenetic Analysis and Post-Analysis of Large Phylogenies. Bioinformatics 10.1093/bioinformatics/btu033.

Uljé CB, Aptroot A, Van Iperen A. 1998 - A new Coprinus from Papua New Guinea sporulating in

Uljé CB. 2005 - Coprinus Pers. In: Flora Agaricina Neerlandica. Noordeloos ME, Kuyper ThW, Vellinga EC. Eds. CRC Press, Boca Raton, Florida. pp. 22-109.

Watling R, Gregory NM. 1987 - 5: Strophariaceae \& Coprinaceae p.p.: Hypholoma, Melanotus, Psilocybe, Stropharia, Lacrymaria \& Panaeolus. In: British Fungus Flora, Agarics and Boleti. Henderson DM, Orton PD, Watling R. Eds. Royal Botanic Garden, Edinburgh, Scotland. pp. 1-121.

White TJ, Bruns T, Lee S, Taylor J. 1990 - Amplification and direct sequencing of fungal ribosomal RNA genes for phylogenetics. In: Innis MA, Gelfand DH, Sninsky JJ, White TJ, eds. PCR Protocols: a guide to methods and applications. San Diego: Academic Press. p. $315-322$. 